\title{
Combinational adenovirus-mediated gene therapy and dendritic cell vaccine in combating well-established tumors
}

\author{
Dajing Xia ${ }^{1}$, Terence Moyana ${ }^{2}$, Jim Xiang ${ }^{1}$ \\ ${ }^{1}$ Research Unit, Health Research Division, Saskatchewan Cancer Agency, Departments of Oncology, Microbiology and Immunology, \\ University of Saskatchewan, 20 Campus Drive, Saskatoon, Saskatchewan S7N 4H4, Canada; ${ }^{2}$ Department of Pathology and Labora- \\ tory Medicine, University of Ottawa, Ottawa, Ontario K1H 8L6, Canada
}

Recent developments in tumor immunology and biotechnology have made cancer gene therapy and immunotherapy feasible. The current efforts for cancer gene therapy mainly focus on using immunogenes, chemogenes and tumor suppressor genes. Central to all these therapies is the development of efficient vectors for gene therapy. By far, adenovirus $(\mathrm{AdV})$-mediated gene therapy is one of the most promising approaches, as has confirmed by studies relating to animal tumor models and clinical trials. Dendritic cells (DCs) are highly efficient, specialized antigen-presenting cells, and DCbased tumor vaccines are regarded as having much potential in cancer immunotherapy. Vaccination with DCs pulsed with tumor peptides, lysates, or RNA, or loaded with apoptotic/necrotic tumor cells, or engineered to express certain cytokines or chemokines could induce significant antitumor cytotoxic T lymphocyte (CTL) responses and antitumor immunity. Although both AdV-mediated gene therapy and DC vaccine can both stimulate antitumor immune responses, their therapeutic efficiency has been limited to generation of prophylactic antitumor immunity against re-challenge with the parental tumor cells or to growth inhibition of small tumors. However, this approach has been unsuccessful in combating well-established tumors in animal models. Therefore, a major strategic goal of current cancer immunotherapy has become the development of novel therapeutic strategies that can combat well-established tumors, thus resembling real clinical practice since a good proportion of cancer patients generally present with significant disease. In this paper, we review the recent progress in AdV-mediated cancer gene therapy and DC-based cancer vaccines, and discuss combined immunotherapy including gene therapy and DC vaccines. We underscore the fact that combined therapy may have some advantages in combating well-established tumors vis-a-vis either modality administered as a monotherapy.

Cell Research (2006) 16:241-259. doi:10.1038/sj.cr.7310032; published online 16 March 2006

Keywords: gene therapy, adenovirus, dendritic cells, vaccine, cytotoxic T lymphocytes, antitumor immunity

\section{Introduction}

A number of different approaches have been developed to generate antitumor effects against neoplasms. Extensive studies have shown that cancer is caused by genetic mutations that are responsible for the neoplastic phenotype of malignant cells [1]. Therefore, it stands to reason that cancer should also be amenable to correction through gene transfer approaches. It thus comes as no surprise that, to

Correspondence: Jim Xiang

Tel: 306 6552917; Fax: 306 6552635;

Email: jxiang@scf.sk.ca date, gene-based cancer treatment protocols have dominated gene therapy trials. In fact, according to the 2004 report of the National Institutes of Health Recombinant DNA Advisory Committee, cancer gene therapy accounts for more than two-thirds of all the gene therapy protocols that have been reviewed [2].

The critical step for the success of gene therapy is the development of an efficient vector system that is able to specifically deliver therapeutic genes into the targeted cells. Up to now, adenovirus (AdV)-mediated gene therapy has been shown to be an attractive approach. However, in the context of cancer gene therapy, its utility in the majority of patients in clinical trials was much limited due to the transient expression of the therapeutic gene and its severe 
side-effects.

Concurrent with the above developments, increasing knowledge concerning the importance of dendritic cells (DCs) in generating immune responses has stimulated attempts to use DCs in cancer vaccines [3]. Recently, immunization with either tumor antigen-presenting DCs or genetically modified DCs has been reported in animal models and clinical trials $[4,5]$. However, the antitumor effect of monotherapy using either gene therapy or DC vaccine against established tumors is still far away from satisfactory. On the other hand, combined immunotherapy using both the above-said modalities may become an effective strategy in the implementation of future clinical objectives.

\section{Gene therapy}

Gene therapy is regarded as transfer of therapeutic genetic material into cells for the purpose of treating or eliminating the causes of a particular disease. Currently, cancer gene therapy mainly uses two types of gene-delivery vectors, namely viral and the non-viral vectors. [6].

The non-viral vectors include naked plasmid DNA, DNA complexed with cationic lipids, and particles comprising DNA condensed with cationic polymers. The advantages of these vectors over their viral counterparts are that they: (i) have no limitation with regard to insert-size, (ii) are less immunogenic, and (iii) are easier to produce. However, a major drawback of non-viral vectors is that their in vivo transfection is not as efficient as those of viral vectors. For this reason, viruses are increasingly being developed as vectors for gene delivery.

Vectors based on retroviruses or AdVs have been used most frequently in cancer gene therapy [7]. Retroviruses integrate their genome into host DNA, and this provides the possibility of long-term transgene expression. However, this random integration may also render the retrovirus vector the potential for insertional mutagenesis in host cells. Retrovirus vectors only transduce dividing cells. Because most cells in vivo are quiescent, the use of retrovirus vectors in cancer gene therapy trials is limited to manipulation of tumor cells ex vivo.

Since their isolation in 1954 [8], AdVs have become a model system for studying gene expression and regulation, DNA replication, regulation of apoptosis, and virus-host interactions [9]. Under natural conditions, AdVs are usually associated with minor human diseases such as upper respiratory tract infections, keratoconjunctivitis and gastroenteritis. Under experimental conditions, early clinical vaccination with wild-type (wt) live AdVs showed no significant side effects, demonstrating their relative safety as vectors for in vivo gene therapy. In recent years, AdVs have been increasingly considered as gene therapy vectors for treating human diseases for the following features: (i) they have been proven safe and effective after being used as live vaccines for immunizing millions of military recruits against acute respiratory infections [10]; (ii) they do not integrate their viral DNA into host chromosomes, thereby avoiding the possibility of disturbing vital cellular genes or inducing cancer as has been the case with retrovirus vectors [11]; (iii) they can modulate dendritic cell maturation by increasing the expression of major histocompatibility complex (MHC) and costimulating molecules [12]; (iv) they can accommodate a large size of foreign DNA of up to $37 \mathrm{~kb}$; and (v) they can be easily produced in large quantities.

To date, several strategies of AdVs-mediated gene therapy have been developed for cancer treatment. They include: (i) AdVs-mediated cytokine or immune accessory molecule gene therapy, (ii) AdVs-mediated tumor suppressor gene therapy and (iii) AdVs-mediated chemogene therapy.

\section{Adenovirus-mediated cytokine or immune accessory mol-} ecule gene therapy

Cytokines such as interleukin-2 (IL-2), gamma interferon (IFN- $\gamma$ ) and alpha tumor necrosis factor (TNF- $\alpha$ ) are important mediators of immune responses against cancer [13-15]. However, the systemic use of these cytokines in cancer patients is limited because of the low concentrations of cytokines in tumors and the severe toxic side-effects derived from high-dose cytokine administration. To improve therapeutic efficacy, cytokine genes have been introduced into tumor cells on the premise that if they can be locally secreted, this would circumvent the limitations associated with their systemic administration.

The foregoing concepts will be highlighted by a number of studies. For example, there are reports documenting the success of in vivo cancer gene therapy in animal models with recombinant $\mathrm{AdVs}$ vectors expressing IL-2 [16, 17], IL-6 [18], IFN- $\gamma[19,20]$ and TNF- $\alpha$ [21]. Significant regression of pre-existing tumors has been observed in these studies, indicating that $\mathrm{AdVs}$ vectors expressing cytokines could potentially form the basis for highly effective cancer gene therapy. However, one of problems observed when using AdVs-mediated cytokine gene therapy is the rapid decline in the cytokine expression within the tumors. This may be due to the local diffusion or absorption of the recombinant AdVs through the vascular system. Therefore, repeated injections of recombinant AdVs in high titers is usually required in order to maintain a high local concentration of the cytokines. However, severe toxicity resulting from vaccination of AdVs expressing cytokines with too high titers has also been reported [17].

Combinational cytokine gene therapy has been used to boost the anti-tumor immunity and at the same time to 
minimize the side-effects of cytokines. IL-12 mediates potent anticancer effects by induction of cytotoxic T lymphocytes (CTLs), Th1-type immune responses, activation of natural killer (NK) cells [22], and by impairment of tumor vascularization [23]. However, the use of IL-12 for the treatment of cancer patients was unsuccessful because of unacceptable dose-related toxicity, which, in some instances, even resulted in fatalities [24]. To overcome this obstacle, Narvaiza and colleagues [25] used a combinational approach which involved the intratumoral (i.t.) coinfection of two AdV vectors encoding IL-12 and interferon-g inducible protein-10 (IP-10) respectively. IP10 is a chemokine that is able to recruit T and NK cells to the tumor cells and impair tumoral angiogenesis [26, 27]. In a mouse colorectal adenocarcinoma model, i.t. injection of AdV vector expressing IL-12 (AdVIL-12) induced tumor regression in nearly $70 \%$ of cases. However, when a suboptimal dose of AdVIL-12 was co-injected with the AdV vector expressing IP-10, 100\% tumor eradication was achieved not only in the locally injected region, but also in distant non-injected tumor sites.

The costimulatory molecule B7-1, which is critical for the generation of $\mathrm{T}$ cell mediated immunity, is also used with IL-12 for combinational treatment of established mouse mammary adenocarcinoma. The AdV vector was constructed by insertion of the IL-12 gene and B7-1 gene into E1 and E3 regions respectively [28]. A single intratumoral (i.t.) injection of the virus expressing both B7-1 and IL-12 at $2.3 \times 10^{7}$ plaque forming units (pfu) per mouse resulted in complete tumor regression in $70 \%$ of treated animals, compared to only $30 \%$ for animals injected with a virus expressing either IL-12 or B7-1. In addition, the cured animals remained tumor free after rechallenge with fresh tumor cells, indicating the presence of a protective immune memory response induced by the combinational treatment. A similar strategy was also used to express lymphotactin and IL-2, or lymphotactin and IL-12, in a single AdV vector [29]. The i.t. injection of these constructs significantly enhanced antitumor immune responses in mouse breast cancer models.

\section{Adenovirus-mediated tumor suppressor gene therapy}

Since most human cancers arise from the loss or mutation of regulatory components in cell-cycle-controlling pathways [30], a major strategy for cancer gene therapy has been developed by restoration of tumor suppressors in cancer cells [31]. For example, mutations in p53 are the most common genetic alterations in cancer cells [32]. In addition, p53 is a potent inducer for triggering apoptosis, and is effective despite the presence of multiple genetic alterations in the cancer cells [33]. Thus, AdV-mediated p53 transfer (AdVsp53) is extensively used for cancer gene therapy. Mutation of the p53 tumor suppressor gene contributes to the progression of human prostate cancer. A mouse model for human prostate cancer was used to study whether introduction of AdVsp53 had any impact on primary tumor growth as well as progression to metastatic disease [34]. Infection of human prostate cancer cells in vitro with $\mathrm{AdVsp} 53$ resulted in marked growth inhibition and apoptosis. In vivo studies demonstrated that a single injection of AdVsp53 into an established prostate tumor resulted not only in primary tumor growth suppression, but also reduced the frequency of progression to metastatic disease. These results suggest that an AdVsp53 gene therapy strategy may prove useful in the treatment of human prostate cancer. The efficacy of AdVsp53 cancer gene therapy has also been demonstrated in other studies [35], and other types of tumors such as breast [28] and brain cancers [36, 37].

Although p53 appears to be an appealing target for cancer gene therapy, other genes involved in the inhibition of cyclin-dependent kinases have been explored for induction of apoptosis in tumor cells. p16 $6^{I N K 4 A}$, which functions as a negative cell-cycle regulator by controlling the activity of CDK4-cyclin D [38], is frequently deleted, mutated, or silenced by promoter methylation in many human cancers [39]. Therefore, restoration of the p16 $6^{I N K 4 A}$ gene in p16-depleted tumor cells would significantly inhibit tumor growth. Based on this concept, AdV-mediated p16 ${ }^{I N K 4 A}$ gene transfer as a cancer gene therapy approach was studied in several types of human cancers with $\mathrm{p} 16^{I N K 4 A}$ deletion, including non-small cell lung cancer, esophageal, prostatic, pancreatic and breast cancers [40-42].

A combined delivery of two tumor suppressor genes has been used to enhance therapeutic efficiency. Sandig and colleagues [43] treated hepatocellular carcinoma by coexpression of $\mathrm{p} 16^{I N K 4 A}$ and $\mathrm{p} 53$ with $\mathrm{AdV}$ vectors. They demonstrated that overexpression of $\mathrm{p} 16^{I N K 4 A}$ results in a blockage of cell division and, subsequently, in a gradual reduction of the levels of $\mathrm{Rb}$ whereas overexpression of both $\mathrm{p} 16^{I N K 4 A}$ and $\mathrm{p} 53$ induces apoptosis in tumor cells. In a mouse hepatocellular carcinoma model, simultaneous AdV transfer of p16 and p53 genes further leads to inhibition of tumor growth in nude mice. Shinoura and colleagues [44] further demonstrated that AdV-mediated transfer of p53 and p33 ${ }^{\mathrm{ING} 3}$, which cooperates with $\mathrm{p} 53$ to block cell proliferation, drastically augments apoptosis in gliomas. Therefore, combined delivery of two cooperating tumor suppressor genes could be the basis for the development of a new strategy for cancer gene therapy.

\section{Adenovirus-Mediated Chemogene Therapy}

In an attempt to avoid side-effects of conventional chemotherapy, AdV vectors have been used to transduce 
tumor cells with the chemogenes encoding an enzyme that converts a nontoxic substance (prodrug) into a toxic molecule. Therefore, chemogene therapy is also called the enzyme/prodrug approach. Since the enzyme encoded by chemogenes is not normally present in human cells, toxins should selectively kill tumor cells transduced by the chemogene as well as the surrounding untransduced cells through a bystander effect.

A variety of genes encoding different types of enzymes have been investigated for their potential use in cancer gene therapy. The most commonly used chemogenes for treatment of various cancers is Herpes Simplex virus thymidine kinase (HSV-TK) with the prodrug gancyclovir (GCV) [45]. The drug GCV is nontoxic as long as it is not metabolized. It is a poor substrate for human TK but is metabolized to monophosphate GCV (MP-GCV) by HSV-TK. Subsequently, cellular enzymes convert MPGCV to triphosphate-GCV, which is incorporated into DNA and RNA. This confers cytotoxicity and cell death by termination of DNA and RNA synthesis. Therefore, tumor cells expressing HSV-TK may be selectively killed by infusion of GCV.

Many articles have documented the utility of i.t. injection of AdVs expressing HSV-TK genes in animal models [46-48]. Having demonstrated a prolonged survival in the murine ovarian cancer model treated with AdV-mediated HSV-TK transfer [49], Alvarez and colleagues [50] further conducted a phase I study to determine the efficacy of this novel approach in patients with recurrent ovarian cancer. Fourteen patients were enrolled in the study. In contrast to brain tumor injections, no dose-limiting toxicity was observed with the intraperitoneal administration of an AdV vector expressing HSV-TK at the dosages studied. The peritoneal cavity thus appears to be fairly tolerant of AdV vector treatment compared to other closed compartments. Of the thirteen patients evaluated, five had stable disease and eight had evidence of progressive disease. The presence of HSV-TK transgene was demonstrated in most patients two days after $\mathrm{AdV}$ vector administration. These results suggest that HSV-TK chemogene therapy is feasible for the treatment of intraperitoneal neoplastic conditions such as metastatic ovarian cancer. Phase I clinical trials using AdVmediated HSV-TK transfer have also been completed for other types of cancer including malignant mesothelioma, prostate cancer, and malignant brain tumors [51, 52].

Another widely used chemogene is the bacterial and fungal gene encoding cytosine deaminase (CD), which deaminates cytosine to uracil and 5-fluorocytosine (5-FC) to 5-fluorouracil (5-FU). Due to the lack of CD in mammalian cells, the $\mathrm{CD}$ gene has become an attractive candidate for chemogene cancer therapy. Transfer of the $\mathrm{CD}$ gene to tumor cells allows conversion of relatively non-toxic 5-FC to 5-FU. The latter inhibits both RNA and DNA synthesis and leads to cell death. AdV-mediated CD gene transfer has been used in gene therapy for various cancers including colon, prostate, and cervical carcinomas [53, 54]. Adachi and colleagues [55] attempted combinational chemogene therapy for brain tumors. They introduced both the $\mathrm{CD}$ gene and the uracil phosphoribosyltransferase (UPRT) gene into rat 9L gliosarcoma cells using $\mathrm{AdV}$ vector, thus encoding the enzyme to convert 5-FU to 5-fluoroluridine 5'-monophosphaste. Coexpression of CD and UPRT renders 9L cells 6000 times more sensitive to 5-FC than the CD gene expression alone. This approach also significantly prolonged animal survival in a rat brain tumor model. Similarly, the $\mathrm{CD}$ gene has also been coexpressed with cytokine genes to increase the cytotoxicity of 5-FC [56].

In the last decade, much progress has been made in AdV-mediated gene therapy of cancer. However, a number of significant problems still confound this treatment modality, namely (i) the failure to efficiently infect certain primary tumor cells which lack AdV receptors such as the Coxackie adenovirus receptor (CAR), and (ii) the promiscuous tropism which causes uncontrolled gene transfer in normal bystander cells. Over and above this, the immune responses associated with gene therapy may lead to other problems such as i) the transient expression of therapeutic gene, ii) non-efficient re-administration of the same vectors, and iii) severe side-effects as has been documented in clinical trials. In an attempt to circumvent or lessen these challenges, various cancer immunotherapeutic strategies are being devised. One such strategy that deserves mention is the DC-based tumor vaccine.

\section{Dendritic cell-based tumor vaccines}

Mature DCs (mDCs) are characterized by having numerous membrane processes that take the form of dendrites, pseudopods, or veils. As the most potent antigen-presenting cells (APC) for primary immune responses, they are also characterized by displaying high levels of MHC class II antigens, and various adhesion and costimulatory molecules (e.g., CD11a, CD11b, CD11c and CD54) on their surface. As with other APCs, the costimulation-associated molecules CD80, CD86, and CD40 are expressed on mDCs, and CD83 is now also recognized as a specific marker for human mDCs. Dendritic cells can process antigens via the classical pathway, whereby endogenous antigens are delivered via proteosomes into the MHC class I compartment, and exogenous antigen via endocytic lysosomes into the MHC class II compartment. However, they also possess an alternative pathway of antigen processing whereby they route exogenous antigen into the MHC class I pathway through a mechanism known as cross-priming. They can 
also utilize molecular chaperones, such as heat shock proteins (HSP), to deliver antigens via the class I pathway [4]. Murine splenic DCs can express CD4 or CD8 markers. It is known that various subsets of DCs exist in humans and mice and that they can play differing roles in the regulation of immune responses $[57,58]$. DCs have also been shown to be capable of inducing strong antitumor immunity [3-5].

Based upon the availability of recombinant cytokines essential for DCs growth and maturation, bone marrowderived DCs (BM-DCs) can now be generated in large numbers simply by culturing BM cells in granulocyte monocyte-colony stimulating factor (GM-CSF) and IL-4 [59]. However, the phenotype of the DCs so generated is critically dependent upon the precise culture conditions. BM cells cultured with low doses of GM-CSF $(2 \mathrm{ng} / \mathrm{ml})$ alone or high doses of GM-CSF and IL-4 (each, 10-20 ng/ $\mathrm{ml}$ ) can differentiate into immature DCs (iDCs) or relatively mature DCs (rmDC) respectively [6]. iDCs lack expression of MHC Class II and costimulatory molecules, while rmDC express intermediate levels of MHC class II and CD80 and low levels of CD40. The rmDC can be induced to full cellular maturity (i.e., $\mathrm{mDCs}$ ) by exposure to stimuli such as LPS, DNA, TNF, HSP or agonistic anti-CD40 antibodies [61-63]; they then express yet higher levels of MHC class II, CD40, CD80, as well as other maturation markers. Injection of Flt3-ligand into humans or mice leads to a substantial expansion of the total DC population [64, 65], while AdV transduction of DC precursors with a GM-CSF gene renders exogenous GM-CSF supplementation unnecessary for the production of mature DCs in culture [66]. Such technical advances, when combined with the increasing knowledge of the important roles DC have in the initiation of immune responses; have provided a compelling impetus for pursuing DC-based immunotherapies for cancer. Here, we briefly summarize recent progress with DC-based cancer vaccines, including tumor antigen-presenting DCs, and genetically-engineered DC vaccines.

\section{Tumor antigen-pulsed DC vaccine}

Tumor-antigen-pulsed DCs have been demonstrated to induce the development of MHC class I- and class IIspecific $\mathrm{T}$ cell responses in vitro and in vivo. DCs pulsed in vitro with peptide antigen and subsequently given to animals can induce antigen-specific, CTL-mediated protection against lethal tumor challenges, and can even induce regression of established tumors [67]. Delivery of the same peptide by DCs can lead to dramatic immunostimulation, while administration of tumor peptides alone can lead to peptide-specific CTL tolerance [68]. Delivery of an array of human and mouse tumor antigens/peptides by DCs can lead to marked antitumor immune responses. Specifically, MHC-restricted synthetic tumor-associated peptides such as melanoma-related antigen, endogenous retroviral gene products gp70/p15E, carcinoembryonic antigen (CEA), folate binding protein (FBP), prostate-specific membrane antigen (PMSA), survivin, MUC-1, HER2/neu and idiotypic protein (Id)-derived peptides, synthetic $b c r-a b l$ b3a2 fusion peptide (ATGFKQSSKALQRPVAS) and a synthetic HPV 16 E7 peptide have been identified. The tumor associated peptides have been delivered to DCs, and used with various degrees of success in animal studies or clinical trials [69-76].

Vaccination strategies directed against a single tumor antigen peptide or epitope may be unduly narrow in scope, with the immune system investing all of its effector resources in a 'single' response. On the other hand, the use of whole tumor lysates as a source of antigen offers the potential advantage of inducing broad-spectrum $T$ cell responses against multiple known, as well perhaps hitherto unknown, tumor-associated antigens expressed within the tumor. As illustrated above, these might induce not only the critical baseline CTL responses, but also helper T cell responses important for a more complete realization of the full antitumor CTL potential. This approach also reduces the work required to identify and generate individual peptides. In two separate strains of mice with histologically distinct tumors, the subcutaneous (s.c.) injection of tumor lysate-pulsed DCs has been shown to effectively prime them for subsequent rejection of lethal challenges with viable parental tumor cells, and also to significantly reduce the number of metastases subsequently established in the lungs of these animals [77]. Furthermore, experimental tumor lysate-DC vaccination has been shown to be effective against hepatocellular carcinoma BNL1MEA.7R.1 (BNL), murine renal cell carcinoma, and syngeneic GL261 gliomas in mice $[78,79]$. Similarly, DCs that have been pulsed with lysates from pancreatic carcinoma cells, malignant brain tumors, or ovarian cancers can induce tumor antigen-specific CTL responses in vitro [80,81]. Most importantly, DC-tumor lysate vaccination of cancer patients has also been shown to be beneficial in the treatment of malignant melanoma, parathyroid carcinoma, advanced breast and uterine cancer, renal cell carcinoma (RCC) and solid tumors [82-86].

\section{Tumor mRNA-pulsed or transfected DC vaccines}

Just as DCs can be treated with tumor peptides or lysates, they can also be pulsed or transfected with tumor RNA. Successfully transfected DCs then translate the respective tumor proteins, with all of the epitopes they encode. After being processed, these tumor antigens would also have the advantage of possessing broader HLA specificities and thus permit the induction of CTL responses almost irrespective of the patient's HLA repertoire. A further advantage of using mRNA is that it can be isolated from murine tumor cell 
lines or from primary human tumor cells microdissected from frozen tissue sections, and amplified at will without loss of function $[87,88]$.

DCs transfected with tumor cell mRNA can stimulate potent CTL responses and engender protective immunity in tumor-bearing mice [87]. Tumor mRNA can be efficiently transfected into DCs, resulting in superior translation product yields in these cells relative to other professional APCs. Most researchers have used mRNA/liposome complexes to transfect DCs, although more efficient mRNA delivery may be achieved by electroporation when using human hematopoietic cells $[89,90]$. Such mRNA-mediated delivery of encoded tumor antigens to DCs can induce potent primary T cell responses in vitro. This is largely because transfection of DCs with tumor mRNA delivers maturation/activation signals to the cells and mediates efficient delivery of antigenic peptides to MHC class I and II molecules. Thus, when used in anti-tumor vaccine strategies, this approach has the potential to powerfully induce tumor-specific effector $\mathrm{T}$ cell activation $[91,92]$. Investigations such as these provide a theoretical foundation for broadly applicable tumor treatments that do not require prior characterization of the relevant antigenic profile for each patient (i.e., the tumor peptides presented by their own HLA haplotype specificities) and would not be limited by the availability of tumor tissues for antigen preparation [88]. Although the total tumor RNA-transfected DC vaccines are still limited in clinical trials $[93,94]$, it may represent a broadly applicable vaccine strategy to induce potentially therapeutic polyclonal T-cell responses in cancer patients.

\section{Necrotic or apoptotic tumor cell-loaded DC vaccines}

DCs can readily take up soluble tumor antigens, such as proteins or immune complexes, but can also phagocytose dying (e.g., apoptotic or necrotic) tumor cells, and thereby induce protective antitumor immunity $[95,96]$. The recognition and uptake of apoptotic cells by DCs is regulated by specific receptors such as aVb5, CD36, or the phosphatidylserine receptor [97], while uptake of necrotic cells is mediated by CD91, the receptor for HSP exposed on these cells $[98,99]$. The advantages of using dying tumor cells as a source of tumor antigens are that: (i) DCs can present or cross-present both MHC class I and II epitopes of a defined tumor antigen or multiple tumor antigens (e.g., MAGE3 and gp100 of melanoma tumors) [100-102]; and (ii) unlike the case with peptide-pulsed DCs, this approach is independent of HLA haplotype and can thus be applied equally to all patients.

The uptake of dying cells decidedly impacts DC maturation. According to the "danger signal" theory of Matzinger [103], the immune system should be activated by internal injuries that signal threats to the organism such as cellular necrosis, but not by signals associated with more "normal" homeostatic processes, such as apoptosis [104]. In this context, it is interesting to note that some reports document that DCs that have captured apoptotic tumor cells induce immunological tolerance to the tumors [105], while other reports indicate that DC phagocytosis of apoptotic tumor cells can also induce effective antitumor immunity [106, 107]. It has now been clearly demonstrated that the stage of the target cell within the apoptotic process affects the maturation of DCs engulfing the cells and thus also the antitumor immunity these cells can induce. Specifically, only tumor cells in the late, but not early, phases of apoptosis stimulate DC maturation and antitumor immunity [108]. Recent comparative analyses have shown that necrotic and late phase-apoptotic cells equally trigger DC maturational changes that lead to the induction of antitumor immunity [109]. As noted above, DC phagocytosis of necrotic tumor cells is dependent on their expression of HSP, as is their subsequent maturation and ability to induce anti-tumor immunity [109-111]. Our results also showed that DCs phagocytosed necrotic/apoptotic tumor cells (as a result of exposure to lovastatin) undergo strong maturation responses, with up-regulated expression of proinflammatory chemokines and cytokines, and co-immunostimulatory molecules. These cells induce stronger protective immunity against tumor challenge in animal models than do DCs pulsed with MHC class I-restricted tumor peptides [112]. Thus, DCs that have phagocytosed apoptotic/necrotic tumor cells appear to offer another new strategy in DC cancer vaccination.

\section{Gene-modified DC vaccines}

Although the approaches described above are encouraging, they are less likely to be applied in the majority of clinical cases largely due to the technical difficulties inherent in the preparation of such materials from human solid tumors. A new strategy, employing genetically modified DCs, has recently been developed for use in DC vaccination. The target genes transferred into the DCs fall into two categories, tumor associated antigens (TAA) and immunomodulatory proteins such as cytokines or costimulatory molecules. Various methods have been used to introduce genes into DCs, including cationic lipids, electroporation, biolistic delivery (i.e., the "gene gun"), complexes of plasmid DNA expression constructs with the cationic peptide CL22, nonviral T7 vector, viral vectors and AdVs/polycation complexes [113-116]. The viral vectors that have been used up to now are poxvirus such as modified vaccinia Ankara (MVA), retrovirus as exemplified by the new lentiviral vectors derived from SIVmac251 (a simian immunodeficiency virus (SIV), herpesvirus, Semliki Forest virus (SFV), influenza virosomes, adeno-associated 
virus, canarypox virus and AdVs [117-120]. From amongst them, the AdV vector was deemed to be a good candidate because of its high efficiency and the attendent minimal risk associated with insertional mutagenesis.

DCs engineered to express tumor-associated antigens The strategy of using genetically modified DCs expressing specific cancer antigens has several advantages over using DCs simply pulsed with tumor antigen proteins or peptides. These include (i) a reduced need to assess the immunologic relevance of individual cancer-specific peptides (as long as the molecules transduced into the DCs are immunogenic), and (ii) the tumor proteins being constitutively-synthesized within the DC will permit specific antigen presentation to $T$ cells for longer periods without generating concerns about the breakdown of peptide/MHC complexes. DCs that express tumor antigen transgenes are also more potent primers of antitumor immune response than their soluble antigen-pulsed counterparts, as determined both in vitro and in animal models [121]. Another advantage of using DCs engineered to express tumor antigens is their potential for generating $\mathrm{CD} 8^{+} \mathrm{T}$ cell responses against multiple class I-restricted epitopes within the antigen, thereby eliciting a broad antitumor effector response [119]. Immunization through ex vivo transduction of DCs has been demonstrated as an effective approach to enhance antitumor immunity by activating $\mathrm{CD}^{+} \mathrm{T}$ cells [122]. MAGE-1, gp100, MART1, hTRP2, p53, MUC-1 and other antigen genes have been used to transfect murine and/or human DCs thereby inducing tumor antigen-specific immune responses [121, 123-127].

Replication-deficient recombinant AdVs encoding human gp100 or MART-1 melanoma antigen have been used to transduce human DCs ex vivo in model systems for cancer vaccine therapy. Human DCs that have been transduced with a replication-defective E1-deleted AdVMART1 produce full-length MART-1 mRNA and protein. In vitro challenges with such DCs stimulated MART- $1_{(27-35)}$-specific tumor-infiltrating lymphocytes to synthesize IFN- $\gamma$ and induced the generation of peptide-specific, MHC class Irestricted CTL within peripheral blood lymphocyte (PBL) from normal donors. A second generation E1/E4 regiondeleted AdV (which harbors the CMV immediate-early promoter/enhancer and a unique E4-ORF6/pIX chimeric gene; Ad2) has also been developed. DC transduced with Ad2/gp100V2 can elicit tumor-specific CTL in vitro from patients bearing gp $100^{+}$metastatic melanoma [128]. Similarly, transduction of an HLA-A2 $2^{+}$MART-1- cell line with AdVMART1 renders these cells sensitive to lysis by CTL specific for the MART- $1_{(27-35)}$ immunodominant peptide [129]. Mice vaccinated with AdVMART1-DCs generated protective responses to lethal tumor challenges with mu- rine B16 melanoma cells. These responses were mediated by MHC class I-restricted, MART-1-specific CTLs which produce high levels of IFN-g when re-exposed to MART1 in vitro, and kill their targets in a manner suggestive of perforin/granzyme-dependent lysis [124].

Genetic immunization using DCs transduced ex vivo with an AdV expressing the HER2/neu gene (AdVNeu) can also induce immunity against a breast tumor cell line overexpressing HER2/neu [130]. Subcutaneous immunization with this $\mathrm{DC}$ vaccine elicited protective immunity from tumor challenge in $60 \%$ of the treated animals, and CTL analyses demonstrated that the animals displayed specific cytotoxic activity against breast tumor cells, as well as syngeneic fibroblasts transduced with AdVNeu. In vivo depletion studies demonstrated that, here too, both $\mathrm{CD}^{+}$ and $\mathrm{CD} 8^{+} \mathrm{T}$ cells were required for effective immunity. In a therapeutic setting, these immunizations could cure mice with established tumors, with the efficacy of this effect being further enhanced by transducing the DCs to express murine IL-12 (AdVmIL-12) [130]. Autologous CD34 hematopoietic progenitor-derived DC retrovirally-transduced with a HER2/neu gene elicited HER2/neu-specific CD8 ${ }^{+}$ CTLs that lyse HER2/neu-overexpressing tumor cells in the context of distinct HLA class I alleles. The induction of both HLA-A2 and -A3-restricted HER2/neu-specific CTLs was verified at the clonal level, and the presence of $\mathrm{CD}^{+}$ Th1 cells recognizing HER2/neu in the context of HLA class II was also documented. These HLA-DR-restricted $\mathrm{CD} 4^{+} \mathrm{T}$ cells were cloned and found to release IFN-g upon stimulation with DCs that had been pulsed with HER2/neu extracellular domain. These data indicate that retrovirallytransduced DCs expressing the HER2/neu molecule present multiple peptide epitopes and elicit HER2/neu-specific CTL and Th1 cells. More importantly, this method of stimulating HER2/neu-specific $\mathrm{CD} 8^{+}$and $\mathrm{CD} 4^{+} \mathrm{T}$ cells with retrovirally-transduced DCs could also be successfully employed for in vitro generation of HER2/neu-specific CTL and Th1 clones from patients with HER2/neu-overexpressing breast cancers. From a conceptual and practical viewpoint, this is a significant advance in the field of DC vaccination therapy since it provides a method for the generation and expansion of HER2/neu-specific, HLA-restricted CTL and Th1 clones in vitro. This should facilitate effective adoptive transfer of autologous HER2/neu-specific T cell clones into patients with HER2/neu-overexpressing tumors without the need to define each tumor's immunogenic peptides [131].

DCs engineered to express immunomodulatory molecules As outlined in detail above, transduction of DCs with tumor antigens offers distinct advantages over simple pulsing of the cells with tumor peptides or lysates. Nevertheless, a notable disadvantage is the painstaking task of selecting an 
appropriate tumor antigen as the DC transduction candidate. MHC haplotype restrictions apply in the presentation of CTL and other epitopes, such that a substantial proportion of the candidate patient base may not be capable of responding to any one chosen peptide/antigen. An alternate strategy has been developed recently to augment the ability of DCs to present tumor antigens, namely transducing them with expression vectors such that they constitutively express immunomodulatory proteins such as cytokines and chemokines. Thus, DCs genetically modified to express a $\mathrm{T}$ cell stimulatory cytokine, for example, could possess adjuvant-like properties useful in the treatment of any number of tumors, so long as sources of TAA were available. It can be argued that one could transduce the tumor cells themselves instead, and count on their subsequent recruitment of APCs. However, since DCs are by nature professional APC designed to deliver their cytokines in precisely the correct context [132], immunomodulatory gene-modified DCs (GM-CSF, TNF- $\alpha$, IL-12, SLC, lymphotactin and CD40L etc.) would represent potentially more potent vaccines than similarly modified tumor cells [133-138].

GM-CSF is an essential in vitro growth and differentiation factor for DCs [59]. The fact that in vivo administration of GM-CSF augments primary immune responses suggests that enforced GM-CSF expression by DCs could perhaps further enhance the effectiveness of DC-based immunotherapy protocols. In vitro, the phenotype of BM-DCs remains largely unaltered by GM-CSF gene transfection, but infection of the DC cell lines XS52-4D and XS106 with AdV-GM-CSF upregulates their expression of MHC and costimulatory molecules as well as their alloantigen or peptide antigen-presenting capacities. On the other hand, when used for in vivo immunizations, the antigen-presenting capacity of GM-CSF gene-transfected BM-DCs was greatly enhanced relative to mock-transfected or untreated DC, as determined by their ability to induce primary immune responses to haptens, protein antigens, or tumor antigens. This increased efficacy correlated with an augmented migratory capacity of GM-CSF gene-transfected BM-DCs in vivo. These data thus suggest that GM-CSF gene transfection may be useful in improving DC-based vaccines currently under clinical investigation [133, 139].

IL-12 is a heterodimeric cytokine produced by many types of cells, including DCs, macrophages, leukocytes, and keratinocytes [140]. It can enhance NK cell and CTL activities, and plays a key role in the induction of Th1-type immune responses. DCs expressing an IL-12 transgene can promote enhanced specific anti-tumor CTL responses compared to nontransduced DC [135]. Similarly, i.t. injection of such IL-12 transduced BM-DCs leads to regression of weakly immunogenic (day 7) established tumors (MCA205, B16, and D122) and to complete regression of established murine transplantable colon adenocarcinomas. This DCIL-12 antitumor effect (and the induction of tumorspecific Th1 responses) is substantially greater than that observed with similarly IL-12-transduced syngeneic fibroblasts or nontransduced BM-DCs. Splenic DCs engineered to express augmented levels of IL-12 also elicit therapeutic antitumor immune responses [141, 142].

Secondary lymphoid tissue chemokine (SLC) is a CC chemokine that is selective in its recruitment of naive $\mathrm{T}$ cells and DCs [143]. In the lymph node, SLC is believed to play an important role in the initiation of immune responses by co-localizing naive $\mathrm{T}$ cells with DCs that are presenting (tumor) antigen. i.t. injection of SLC-expressing DCs $\left(\mathrm{DC}_{\mathrm{SLC}}\right)$ results in tumor growth inhibition that is significantly better than observed with either control DCs or SLC alone. Similarly, distant site immunization of tumor-bearing mice with $\mathrm{DC}_{\mathrm{SLC}}$ that have been pulsed with tumor lysates elicits antitumor responses, whereas controls DCs do not. Direct administration of $\mathrm{DC}_{\mathrm{SLC}}$ into growing B16 melanomas induces a substantial and sustained influx of $\mathrm{T}$ cells into the tumor mass, and there is only transient increase in $\mathrm{T}$ cell numbers in the draining lymph node (DLN). This suggests that the DCs are largely retained at the tumor sites, with only a very small proportion of them trafficking to the DLN. Within 24 hours, the T cells infiltrating the tumors express the activation marker CD25, and by 7 days they will have developed an IFN- $\gamma$-secreting function, in concert with a detectable inhibition of tumor growth. These reports demonstrate that SLC expression by DCs can induce antitumor responses that lead to enhanced antitumor immunity [136].

\section{Combined AdV-mediated cancer gene therapy and DC-based tumor vaccines}

To date, the therapeutic efficiency of DC vaccine strategies remains limited to the generation of prophylactic antitumor immunity against re-challenge with the parental tumor cells. In clinical practice, most candidates for cancer therapy are patients with a sizable tumor load. Therefore, immunotherapeutic strategies aimed at directly combating well established tumors as seen in real clinical situations are of value in translational research. Unfortunately, at present, most of the current mono-immunotherapeutic protocols, such as AdV-mediated gene therapy or DC-based tumor vaccines, have failed in combating well-established tumors in animal models. This lack of success is likely related to a combination of events, including the somewhat inefficient antitumor immune responses induced by the therapy, and the tumor growth rapidly out-stripping the ability of the patient's immune system to effectively deal with it $[144,145]$. Thus, a major strategic goal of current cancer 
immunotherapy has become the development of novel therapeutic strategies combating well-established tumors. A combined immunotherapy including gene therapy and DC vaccines would have some advantages over each modality administered as a monotherapy. Recently, our lab has focused on induction of antitumor immunity by combined immunotherapy including DC vaccines and AdV-mediated cytokines gene therapy such as TNF- $\alpha$, CD40L etc $[146,147]$.

Combination of AdVTNF- $\alpha$ and engineered DC vaccine efficiently eradicate well-established melanoma

Substantial evidence has now proven that TNF- $\alpha$ is a multifunctional and immunoregulatory cytokine that has antitumor activity, evokes apoptosis, up-regulates adhesion molecules, and activates immune cells such as macrophages, DCs, neutrophils and T cells [148]. Since its antitumor properties have been demonstrated in a variety of in vivo experimental models, TNF- $\alpha$ has attracted attention as a potential antitumor reagent [149-151]. Unfortunately, the systemic administration of recombinant TNF- $\alpha$ protein in human cancer clinical trails has been limited by the problem of dose-related toxicity since the maximal tolerated dose of TNF- $\alpha$ in humans is 40 -fold less compared to mice on a weight-for-weight basis [152]. Severe side effects are therefore commonly encountered in cancer patients receiving TNF- $\alpha$ treatment. These include a septic-like shock syndrome, hypotension, malaise, diarrhea, leukothrombopenia, and anorexia. [152-154]. To induce a high local concentration of TNF- $\alpha$ while limiting the systemic use of high dose TNF- $\alpha$, a technique utilizing isolated limb perfusion with TNF- $\alpha$ has been applied [155].

Gene therapy by using both in vitro and in vivo gene transfer strategies provides a useful means for the local transgene expression of TNF- $\alpha$ within tumors. Tumor cells transduced with the TNF- $\alpha$ gene in vitro displayed loss of their tumorigenicity, and vaccines based on these engineered tumor cells can inhibit tumor growth when re-challenging parental tumors in immunized mice by activated immune responses [156, 157]. However, these in vitro strategies are cumbersome to use in humans due to the critical requirements of culturing the autologous tumor cells from patient's neoplasm as well as genetically modifying tumor cells with the TNF- $\alpha$ gene prior to its administration. An alternative is the direct in vivo gene delivery mediated by AdVs expressing TNF- $\alpha$. It has been reported that the i.t. administration of AdVTNF- $\alpha$ resulted in transgene expression of TNF- $\alpha$ in tumors, detection of serum TNF- $\alpha$ within one day to two days, and regression of small palpable tumors within two days to three days in treated mice. However, the well-established experimental tumors did not regress, though their growth was much slowed down [158-160].

The above concepts are borne out in our studies. We developed a novel immunotherapy combined AdVTNF$\alpha$-mediated gene therapy with a TNF- $\alpha$-gene modified DC vaccine $\left(\mathrm{DC}_{\mathrm{TNF}-\alpha}\right)$. We went on to investigate its therapeutic efficiency in the treatment of well-established MO4 tumors expressing tumor antigen OVA in animal models, and compared it to either gene therapy or DC vaccine alone [146]. As shown in Figure 1, vaccination of $\mathrm{DC}_{\mathrm{TNF}-\alpha}$ cells pulsed with the OVA I peptide could stimulate a type 1 immune response with enhanced antitumor CTL activities. While $\mathrm{DC}_{\mathrm{TNF}-\alpha}$ vaccine could induce protective immunity against challenge of $5 \times 10^{5} \mathrm{MO} 4$ tumor cells, and reduce the growth of the small (3-4 $\mathrm{mm}$ in diameter), it failed to eradicate any of the large tumors $(6-8 \mathrm{~mm}$ in diameter). However, it did manage to significantly reduce the rapid tumor growth in the latter group of mice. Almost all tumors showed apparent regression within 5 days subsequent to i.t. injection of AdVTNF- $\alpha$ due to sizable tumor necrosis caused by intravascular thrombosis (Figure 2). However, they rapidly regrew, leading to the death of the mice within approximately another two weeks to three weeks. Our histological data also showed that, invariably, there were residual cancer cells at the edges of necrotic areas of the large tumors (Figure 2), and these are the likely the sources of tumor recurrence. The data from the in vivo study showed that AdVTNF- $\alpha$-mediated gene therapy eradicated small tumors in 6 out of $8(75 \%)$ mice, and the mechanism for this appeared to be massive tumor necrosis. In contrast, none of the large tumors $(0 \%)$ were destroyed. Interestingly, a combined AdVTNF- $\alpha$-mediated gene therapy and TNF- $\alpha$-gene-engineered $\mathrm{DC}_{\mathrm{TNF}-\alpha}$ vaccine cured 3 out of 8 (38\%) mice bearing large MO4 tumors, indicating that the combined immunotherapy strategy is much more efficient in combating well-established tumors than monotherapy of either gene therapy or DC vaccine alone (Figure 3 ).

Co-administration of iDCs following the AdVCD40L elicits significant regression of established myeloma

CD40 ligand (CD40L) is a $33-\mathrm{kDa}$ type II membrane protein that is a member of TNF gene family. It is preferentially expressed on activated $\mathrm{CD} 4^{+} \mathrm{T}$ cells [161]. The receptor for CD40L is the CD40 molecule (a member of the TNF receptor family) expressed on APCs, including DCs [162].

The functions of DCs such as Ag capture, Ag presentation and migration have been shown to change dynamically as their maturation progresses [163, 164]. Amongst the multitudinous stimuli for DC maturation, CD40 is one of the most important. In fact, the major $\mathrm{CD}^{+} \mathrm{T}$ cell help signal for DC maturation is provided by the interaction between CD40 expressed on DCs and CD40L on activated 
A

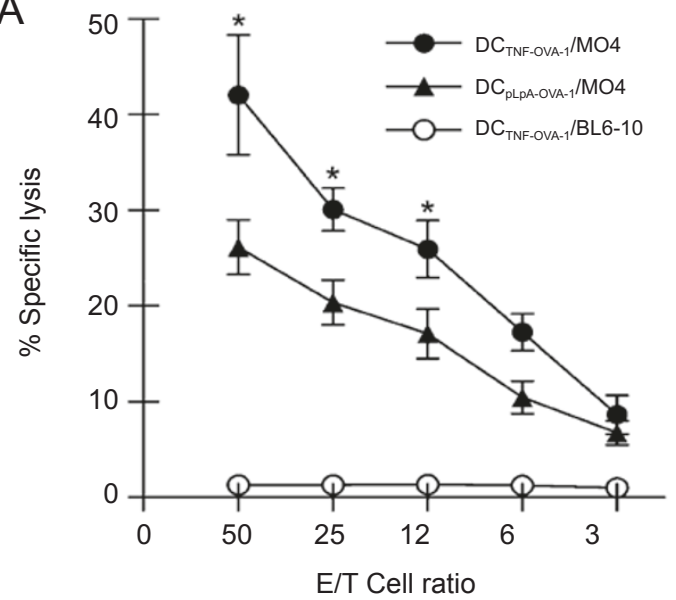

B

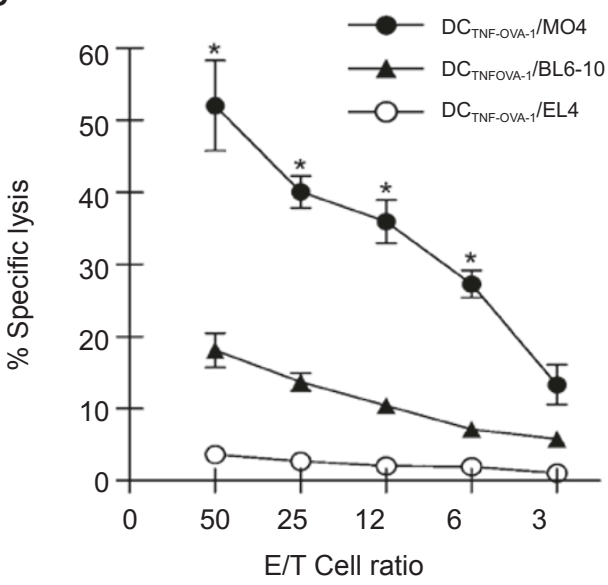

Figure 1 Cytotoxicity assay. (A) In the first experiment, splenic lymphocytes from OVA I-pulsed DC $\mathrm{TNF}_{\mathrm{TN}-\alpha}\left(\mathrm{DC}_{\mathrm{TNF}-\alpha-\mathrm{OVA}-\mathrm{I}}\right)$ or $\mathrm{DC}_{\mathrm{pLpA}}$ $\left(\mathrm{DC}_{\mathrm{pLPA}-\mathrm{OVA}-\mathrm{I}}\right)$ vaccinated mice were stimulated in vitro for $4 \mathrm{~d}$ with irradiated MO4 tumor cells, and then used as effector (E) cells in a chromium release assay. In the assay, ${ }^{51} \mathrm{Cr}$-labeled MO4 tumor cells with OVA expression were used as target (T) cells. To confirm that the $\mathrm{T}$ cell cytotoxicity was MO4-tumor-specific, we also included BL6-10 tumor cells (without OVA expression) as a target control with activated T cells from $\mathrm{DC}_{\mathrm{TNF}-\alpha}$-vaccinated mice. $* P<0.05$ versus cohorts immunized with ${ }^{*} C_{\mathrm{pLpA}-\mathrm{OVA}-\mathrm{I}}$. $(\mathrm{B})$ In the second experiment, splenic lymphocytes from mice with tumor regression (as a result of treatment with combined gene therapy and DC vaccine) were stimulated in vitro for 4 days with irradiated MO4 tumor cells, and then used as effector (E) cells in a chromium release assay. In the assay, ${ }^{51} \mathrm{Cr}$-labeled MO4, BL6-10 and EL4 tumor cells were used as target (T) cells. ${ }^{*} P<0.05$ versus cohorts of BL6-10 tumor cells as target cells. Each point represents the mean of three triplicates.

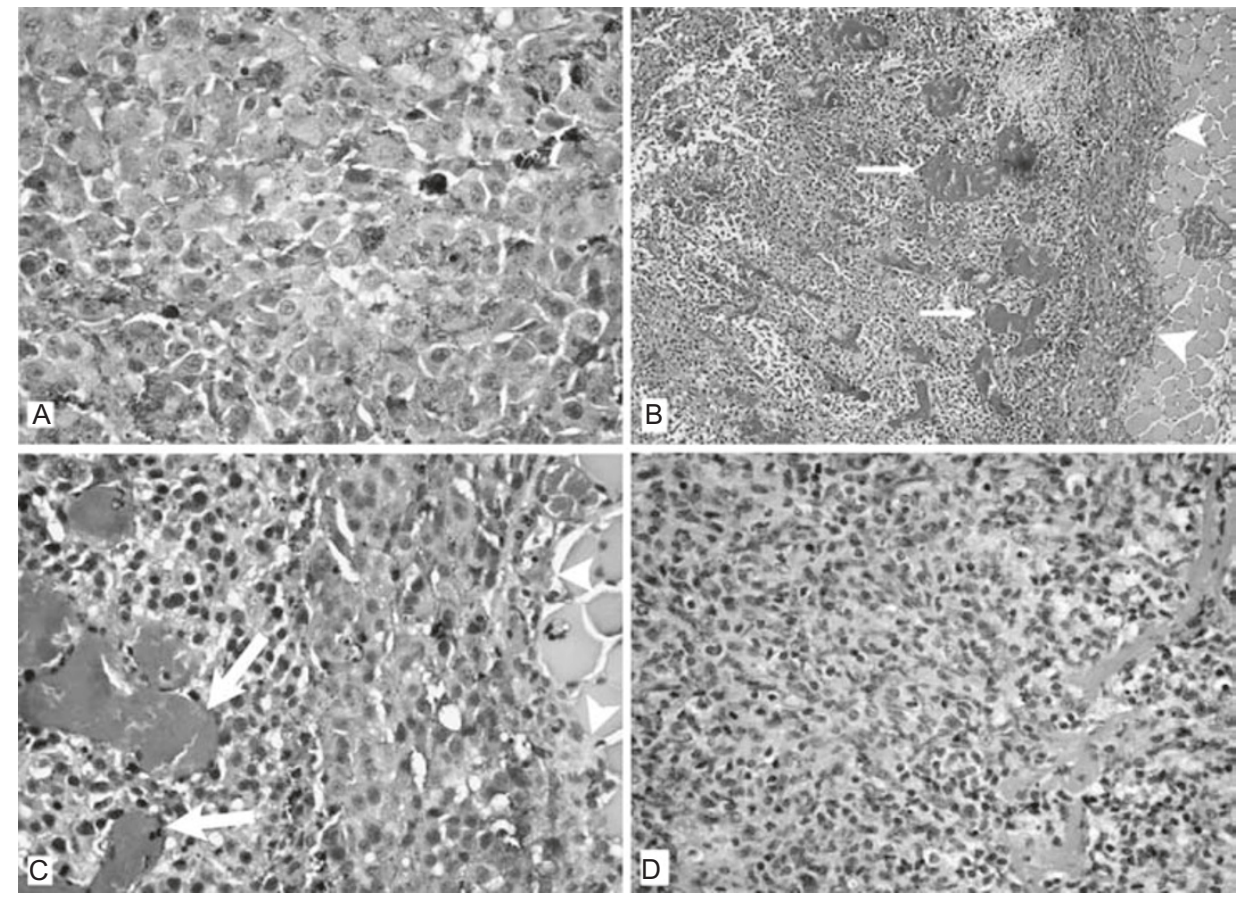

Figure 2 Histologic photomicrographs of tumors and/or lesions. Tumor nodules at the injection sites were removed, fixed in $10 \%$ formaldehyde and embedded in paraffin for histological analysis $1 \mathrm{~d}$ and $8 \mathrm{~d}$ subsequent to the injection of AdVTNF- $\alpha$. Sections of 6-7 (Jim: 6-7 microns sounds quite thick; it is usually 4-5 microns. But you can leave it like that if it is really 6-7) mm thickness were stained with hematoxylin-eosin according to the standard procedures. (A) Photomicrograph from a MO4 tumor showing numerous melanoma cells. (B, C) Photomicrograph from a MO4 tumor at d 1 after i.t. injection of $2 \times 10^{9}$ PFU AdVTNF showing extensive tumor necrosis with some residual tumor cells at the edges of the lesion (arrow heads) and intravascular thrombosis (arrows). (D) Photomicrograph from a regressed MO4 TS1 tumor at d 8 after the AdVTNF injection displays mostly mononuclear cells and fibroblasts, but no tumor cells. Magnification was $\times 200$ for all except for B which $\times 100$. 


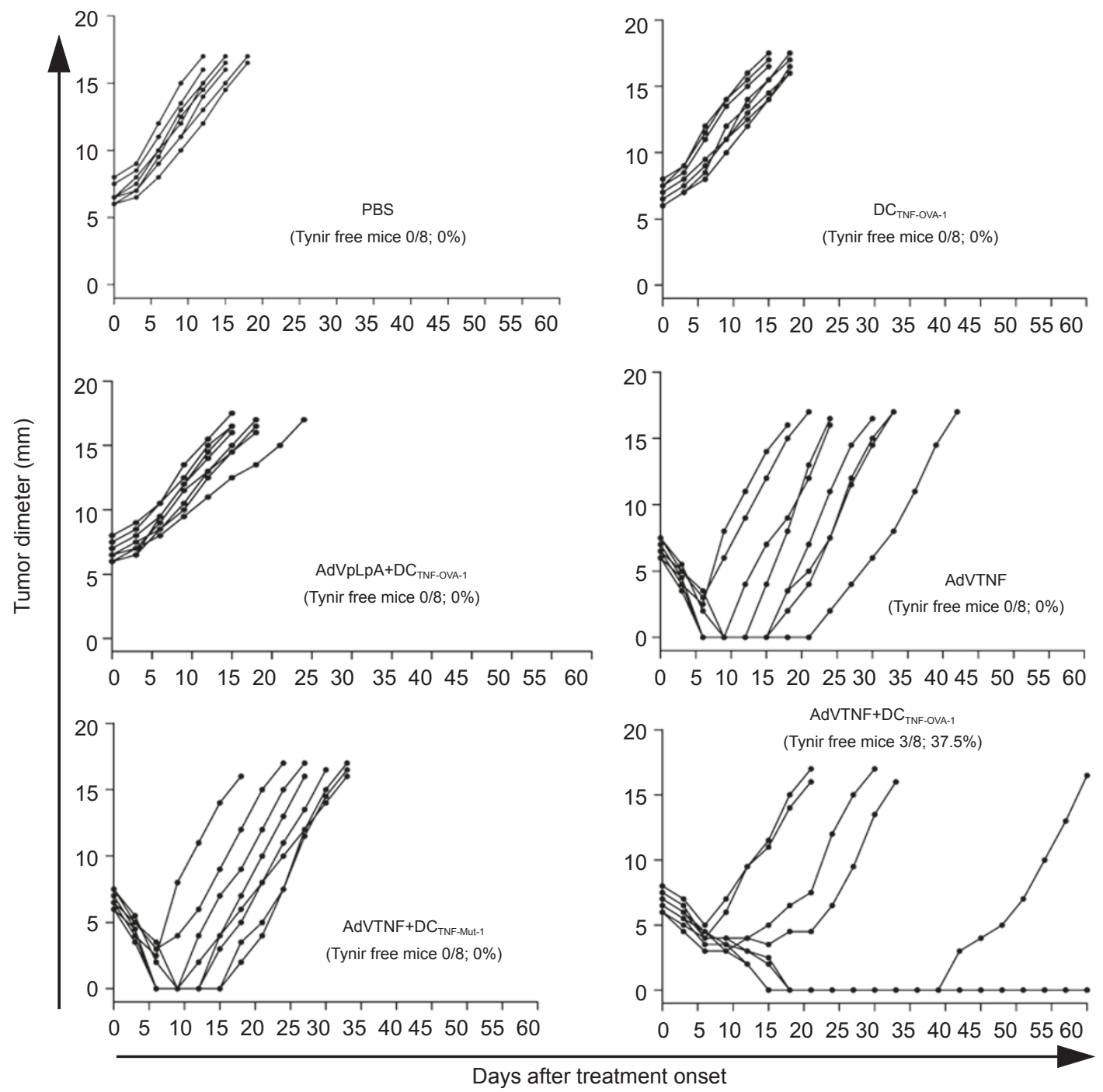

Figure 3 Impact of combined gene therapy and DC vaccine on the growth of well-established tumors in mice. Mice bearing wellestablished MO4 tumors ( $6 \mathrm{~mm}-8 \mathrm{~mm}$ in diameter) were given i.t. injection of AdVTNF- $\alpha$ or AdVpLpA $\left(2 \times 10^{9} \mathrm{pfu}\right)$ in conjunction with subcutaneous OVA I- or Mut 1-pulsed $\mathrm{DC}_{\mathrm{TNF} \alpha}\left(\mathrm{DC}_{\mathrm{TNF}-\alpha-\mathrm{OVA}-\mathrm{I}}\right.$ or $\left.\mathrm{DC}_{\mathrm{TNF}-\alpha-\mathrm{Mut}-1}\right)$ vaccines three times. Another three control groups of mice were given i.t. injection of PBS or control AdVpLpA alone or subcutaneous $\mathrm{DC}_{\mathrm{TNF}-\alpha}\left(\mathrm{DC}_{\mathrm{TNF}-\alpha-\mathrm{OVA}-\mathrm{I}}\right)$ vaccines alone. Tumor growth was monitored and the tumor size (diameter) measured using an engineering caliper. The evolution of the tumors in individual mice are depicted, as are the fractions of mice in each treatment group that were tumor-free at 60 days post-treatment.

$\mathrm{CD}^{+} \mathrm{T}$ cells $[162,165]$. It has been shown that that mice lacking CD40L were associated with immunodeficiency accompanied by an impaired migration of DCs into secondary lymphoid tissues [166], thus reinforcing the notion that CD40 stimulation is indispensable for DCs maturation. It is well known that, for antitumor immunity to be effective, the $\mathrm{CD} 8^{+} \mathrm{T}$ cells must recognize tumor Ag-peptides bound to MHC class I expressed on the tumor cells. However, for $\mathrm{CD}^{+} \mathrm{T}$ cells to acquire the ability to destroy the tumor cells, the DCs presenting the $\mathrm{Ag}$ must receive the $\mathrm{CD} 4^{+}$ $\mathrm{T}$ cell help signal $[167,168]$. The functions of DCs are mainly dependent on their state of activation and differentiation, i.e., iDCs can avidly capture Ags, while mDCs can efficiently induce CTL cytotoxicity. However, the most optimal method for conditioning DCs for anticancer immunotherapy is not entirely clear. Watanabe $\mathrm{S}$ and his colleagues found that iDCs had significant advantages over mDCs in anticancer immunotherapy due to their ability to prime $\mathrm{T}$ cells in secondary lymphoid organs through immobilized anti-CD40 antibody stimulation in the in vitro model [169]. Therefore, we hypothesized that AdVCD40L i.t. injection might have the ability to inhibit 


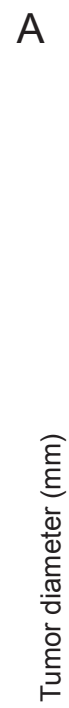

PBS

(Tumor free mice 0/10; 0\%)

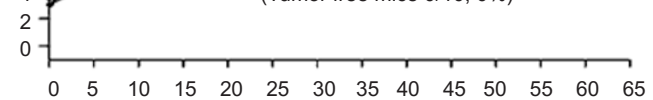

$\begin{array}{llllllllllllll}0 & 5 & 10 & 15 & 20 & 25 & 30 & 35 & 40 & 45 & 50 & 55 & 60 & 65\end{array}$

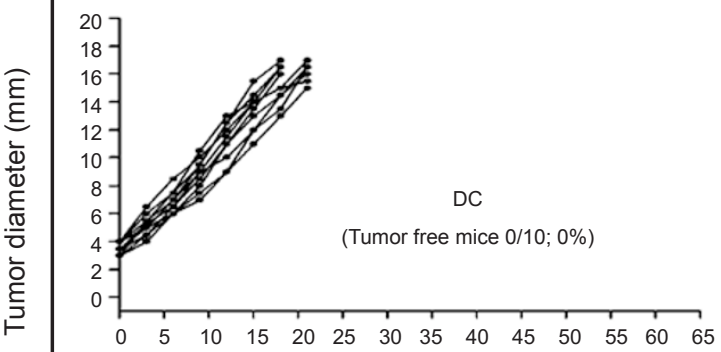

(Tumor free mice $0 / 10 ; 0 \%$ )

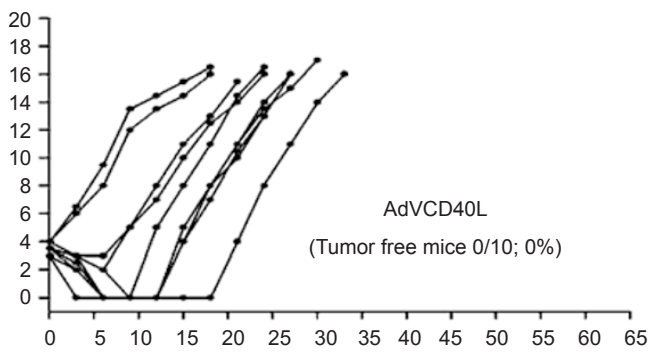

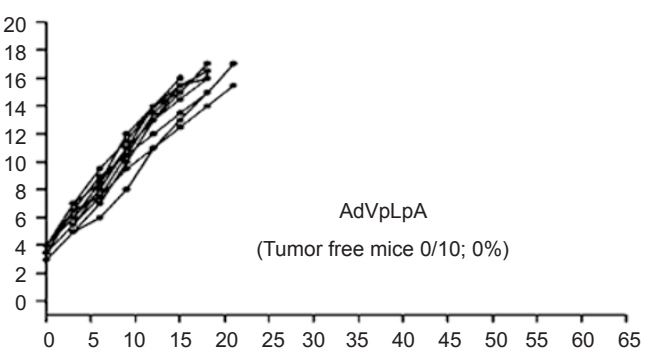
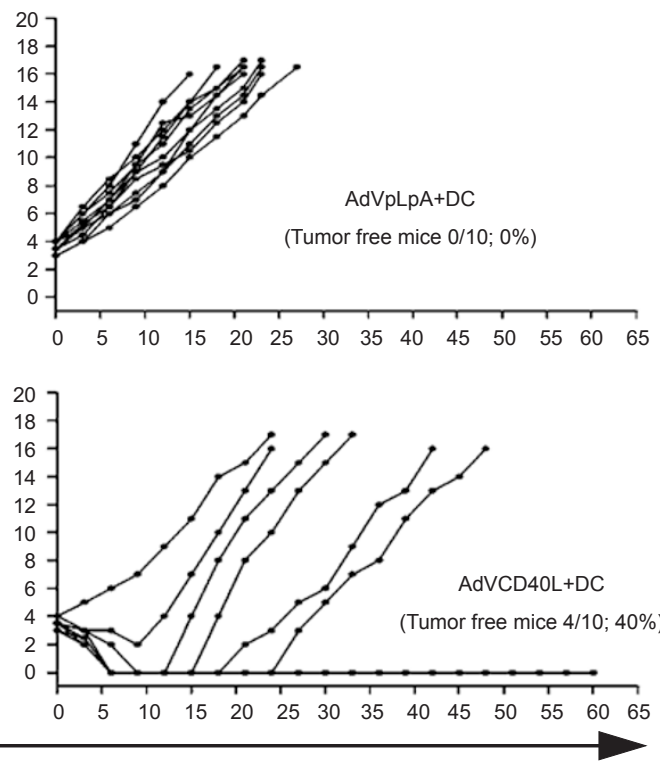

Days after treatment onset

B

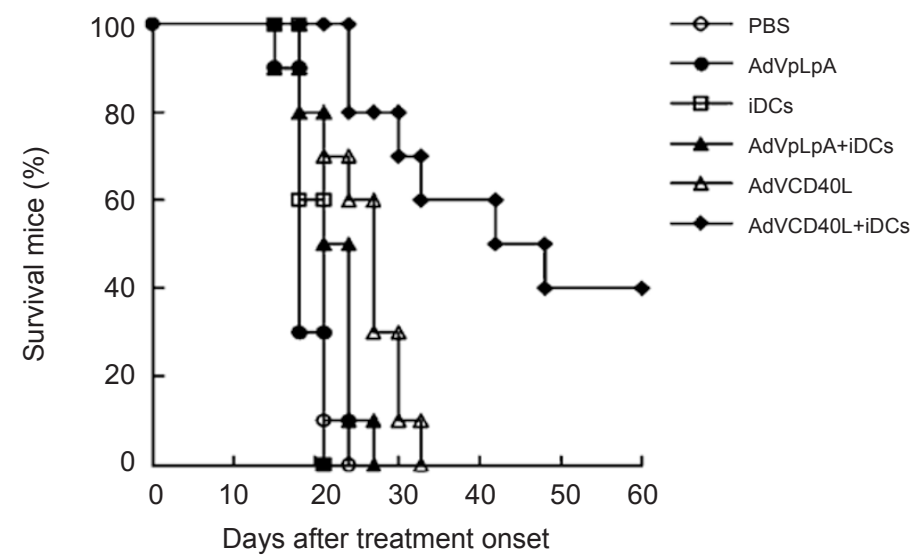

Figure 4 Inhibition of tumor growth (in mice with established tumors) by treatment with AdVCD40L and iDCs vaccine. Mice bearing well-established J558 tumors ( $3 \mathrm{~mm}-4 \mathrm{~mm}$ in diameter) were first given intratumoral injection of AdVCD40L or AdVpLpA (5 $\times$ $10^{9} \mathrm{pfu}$ ), followed 2 days later by i.t. injection with iDCs. Another four control groups of mice were given, respectively, intratumoral injection of PBS, iDCs, control AdVpLpA, or AdVCD40L alone. (A) Tumor growth was monitored and the tumor size (diameter) measured using a caliper. The evolution of the tumors in individual mice is depicted, as are the fractions of mice in each treatment group that were tumor free at 60 days post-treatment. (B) Tumor-bearing mice were observed for the duration of their survival period.

J558 tumor growth and induce tumor cell apoptosis in vivo. Based on this hypothesis, we set up experiments whereby
iDCs were injected into tumor tissues to phagocytose the apoptotic cells or apoptotic bodies. CD40L expression in 


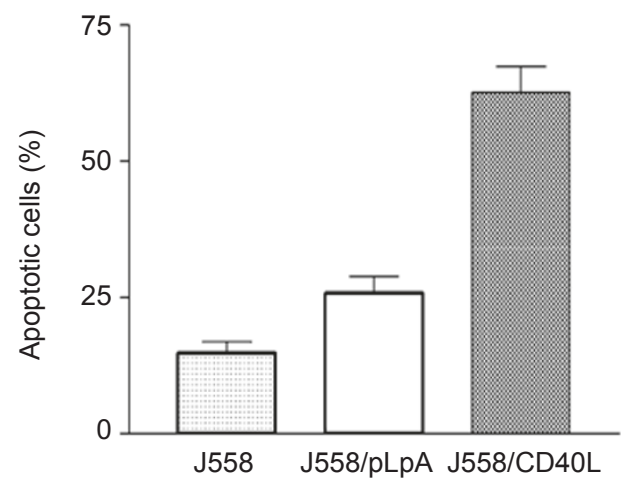

Figure 5 CD40L-induced apoptosis in J558 cell line. After transfection with AdVCD40L, apoptosis of J558 cells was measured by cell staining with FITC-Annexin-V antibody and propidium iodide according to the manufacturer's instruction. Data represent the mean \pm S.D. of three independent experiments.

the tumor microenvironment thus stimulated the iDCs that had engulfed the apoptotic bodies to migrate to the lymph nodes for maturation. The mDCs then effectively primed and activated the $\mathrm{T}$ lymphocytes.

More recently, to induce antitumor immunity in an established myeloma model [146], we investigated the strategy using i.t. injection iDCs following AdVCD40L vaccination. Our results demonstrated that, 2 days following AdVCD40L injection, i.t. treatment with iDCs not only significantly suppressed tumor growth but also eradiated the established tumors in $40 \%$ of the mice (Figure 4 ). The potent antitumor effect produced by the combination therapy correlated with high expression of MHC, costimulatory and Fas molecules on J558 cells, which was derived from CD40L transgene expression. In addition, transgene CD40L expression could dramatically induce J558 cell apoptosis. The study of the related mechanism demonstrated that the apoptotic rate of J558/CD40L cells was significantly increased after transduction with the AdVCD40L compared with untransfected $\mathrm{J} 558$ or J558/pLpA cells $(62.5 \%$ vs $14.9 \%, 25.7 \%$ ) (Figure 5). iDCs that effectively captured apoptotic bodies in vivo could induce DC maturation. Since the J558/CD40L cells contained a population of apoptotic cells, the uptake of apoptotic bodies derived from tumor cells by iDCs was evaluated. The enhanced ability of iDCs
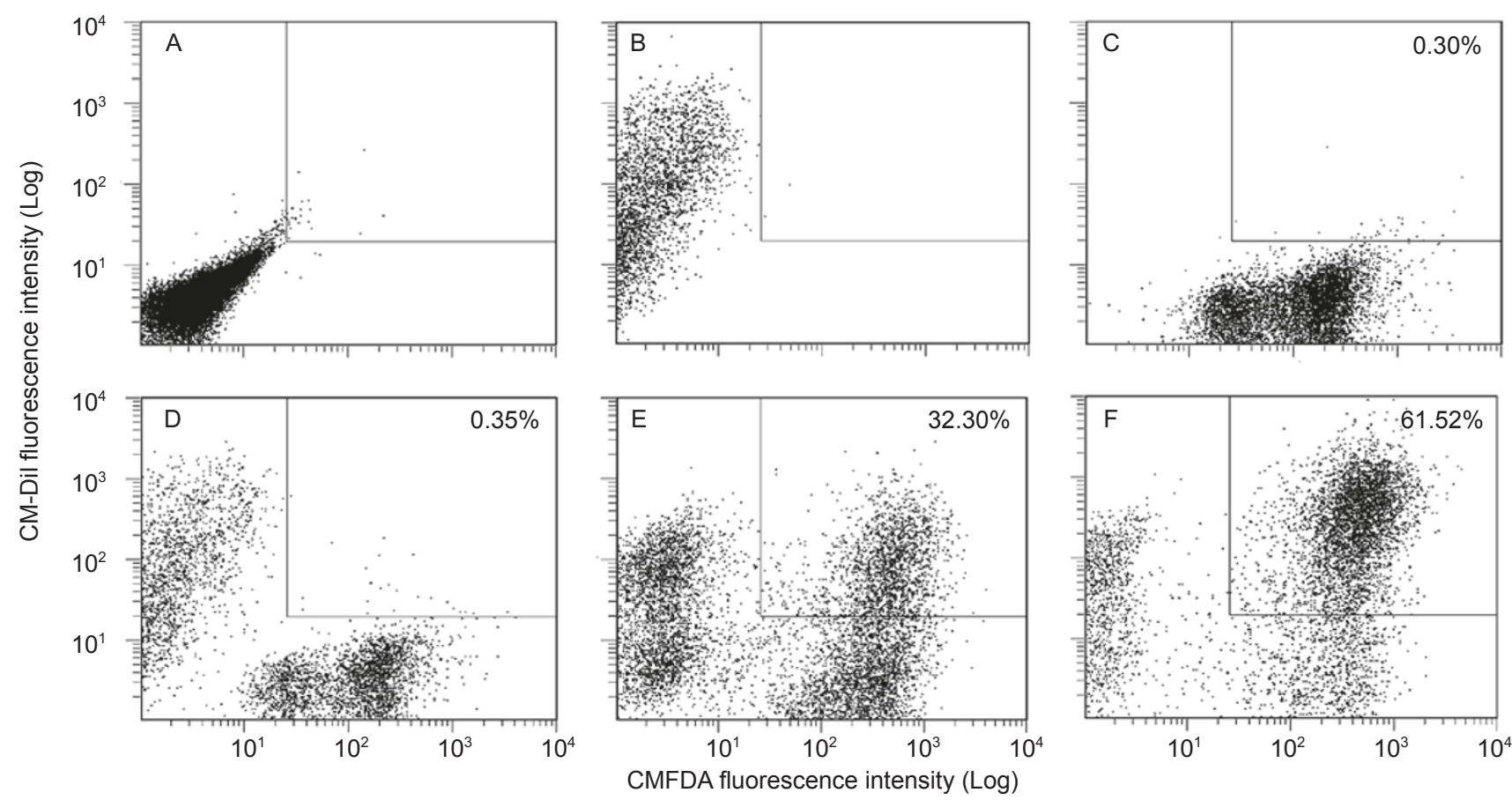

Figure 6 Uptake of apoptotic bodies derived from J558/CD40L by DCs. iDCs labeled with the CMFDA green fluorescent cell linker compound were co-cultured with J558/CD40L at a 1:1 ratio. They were recovered after transfection with AdVCD40L for 24 h, and then labeled with CM-DiI red fluorescent cell linker compound. The cells were analyzed by flow cytometry. A, negative (none-dying) DCs; B, J558/CD40L dying with CM-DiI; C, iDCs dying with CMFDA; D, E and F illustrate the uptake of apoptotic bodies by DCs at $37^{\circ} \mathrm{C}$ for $0 \mathrm{~h}, 4 \mathrm{~h}$ and $24 \mathrm{~h}$, respectively. The number shows the percent of dual color DCs, which have engulfed the apoptotic bodies of J558/CD40L cells. 
to capture apoptotic bodies was observed in J558/CD40L cells and/or iDCs stained with red fluorescent CM-DiI and/or green fluorescent CMFDA. As shown in Figure 6 , the percent of double positive cells was $32.3 \%$ and $61.5 \%$ after interaction with $\mathrm{J} 558 / \mathrm{CD} 40 \mathrm{~L}$ for $4 \mathrm{~h}$ or $24 \mathrm{~h}$, respectively. The effective capture of apoptotic bodies by iDCs in vivo could induce DC maturation, which in turn primed Th1 and tumor-specific CTL immune responses. To further elucidate the immune mechanism involved in the therapeutic immunity of AdVCD40L and iDCs vaccines, activated $\mathrm{T}$ cells were prepared as follows: splenocytes from mice were i.t. co-injected with AdVsCD40L and iDCs for two weeks, and then stimulated with irradiated J558 tumor cells for 4 days. These $T$ cells were then subjected to phenotypic characterization by flow cytometry. The results showed that the activated $\mathrm{T}$ cells from mice treated with AdVCD40L and iDCs displayed a higher expression of T cell active marker (CD25) and costimulatory molecules CD40L when compared to T cells from the control mice. Interestingly, the FasL molecule was also significantly up-regulated. In summary, our data demonstrated that AdVmediated CD40L gene therapy induced $\mathrm{CD} 40^{+}$myeloma cells apoptosis and favored the maturation of iDCs through capturing the apoptotic cells, thus efficiently increasing the killing activity of tumor specific $\mathrm{T}$ lymphocytes. Therefore, it would appear that the sequential administration of AdVCD40L and iDCs may become a better paradigm for antitumor therapy.

\section{Summary}

Studies of the molecular pathogenesis and immunology of tumors have paved the way for the entrance of cancer gene therapy and immunotherapy into the mainstream of cancer treatment. Although the results of gene therapy or $\mathrm{DC}$ vaccines have been quite intriguing and provocative to date, the therapeutic efficiencies of these modalities are still far from satisfactory in well-established tumor animal models or most patients in clinical practice. Our findings and those of other investigators highlight the advantages of combined immunotherapy including AdV-mediated TNF- $\alpha$ or CD40L-gene therapy and DC vaccines in combating well-established tumors in animal models. This novel combined immunotherapeutic strategy may thus become a tool of considerable conceptual interest in the implementation of future clinical objectives. However, the potential benefits of administering cytokines or other DC activators in combination with $\mathrm{DC}$ vaccination remain to be further investigated.

\section{References}

1 Bishop JM. Cancer: the rise of the genetic paradigm. Genes
Dev 1995; 9:1309-1315.

2 http://www4.od.nih.gov/oba/rac/PROTOCOL.pdf. HUMAN GENE TRANSFER PROTOCOLS. Last updated: Sep-13-04.

3 Figuredor CG, de Vries IJ, Lesterhuis WJ, Melief CJ. Dendritic cell immunotherapy: mapping the way. Nat Med. 2004; 10:475480.

4 Fong L, Engleman EG. Dendritic cells in cancer immunotherapy. Annu Rev Immunol 2000; 18:245-273.

5 Cranmer LD, Trevor KT, Hersh EM. Clinical applications of dendritic cell vaccination in the treatment of cancer. Cancer Immunol Immunother 2004; 53:275-306.

6 Romano G, Pacilio C, Giordano A. Gene transfer technology in therapy: current applications and future goals. Stem Cells 1999; 17:191-202.

7 Dyer MR, Herrling PL. Progress and potential for gene-based medicines. Mol Ther 2000; 1:213-224.

8 Hilleman MR, Werner JH. Recovery of new agent from patients with acute respiratory illness. Proc Soc Exp Biol Med. 1954; 85:183-188.

9 Shenk T. Adenoviridae: The viruses and their replication. In: Knipe DM, Fields, BN, Howley PM, Eds. Fields virology, $3^{\text {rd }}$ ed. Lippincott-Raven: Philadelphia, Pa, 1996:2111-2148.

10 Gaydos CA, Gaydos JC. Adenovirus vaccine. In: Orenstein WA, Eds. Vaccines (ed 4th Edition). Philadelphia: Saunders; 2004:863-885.

11 Dave UP, Jenkins NA, Copeland NG. Gene therapy insertional mutagenesis insights. Science 2004; 303:333.

12 Molinier-Frenkel V, Prevost-Blondel A, Hong SS, et al. The maturation of murine dendritic cells induced by human adenovirus is mediated by the fiber knob domain. J Biol Chem 2003; 278:37175-37182.

13 Lee J, Fenton BM, Koch CJ, Frelinger JG, Lord EM. Interleukin 2 expression by tumor cells alters both the immune response and the tumor microenvironment. Cancer Res 1998; 58:14781485.

14 Abdel-Wahab Z, Dar M, Osanto S, et al. Eradication of melanoma pulmonary metastases by immunotherapy with tumor cells engineered to secrete interleukin-2 or gamma interferon. Cancer Gene Ther 1997; 4:33-41.

15 Kianmanesh A, Hackett NR, Lee JM, et al. Intratumoral administration of low doses of an adenovirus vector encoding tumor necrosis factor alpha together with naive dendritic cells elicits significant suppression of tumor growth without toxicity. Hum Gene Ther 2001; 12:2035-2049.

16 Addison CL, Braciak T, Ralston R, et al. Intratumoral injection of an adenovirus expressing interleukin 2 induces regression and immunity in a murine breast cancer model. Proc Natl Acad Sci U S A 1995; 92:8522-8526.

17 Toloza EM, Hunt K, Swisher S, et al. In vivo cancer gene therapy with a recombinant interleukin-2 adenovirus vector. Cancer Gene Ther 1996; 3:11-17.

18 Tanaka F, Abe M, Akiyoshi T, et al. The anti-human tumor effect and generation of human cytotoxic T cells in SCID mice given human peripheral blood lymphocytes by the in vivo transfer of the Interleukin-6 gene using adenovirus vector. Cancer Res 1997; 57:1335-1343.

19 Gattacceca F, Pilatte Y, Billard C, et al. Ad-IFN gamma induces antiproliferative and antitumoral responses in malignant mesothelioma. Clin Cancer Res 2002; 8:3298-3304.

20 Ahmed CM, Sugarman BJ, Johnson DE, et al. In vivo tumor 
suppression by adenovirus-mediated interferon alpha2b gene delivery. Hum Gene Ther 1999; 10:77-84.

21 Xiang J, Chen Y, Moyana T. Combinational immunotherapy for established tumors with engineered tumor vaccines and adenovirus-mediated gene transfer. Cancer Gene Ther 2000; 7:1023-1033.

22 Trinchieri G. Interleukin-12 and the regulation of innate resistance and adaptive immunity. Nat Rev Immunol 2003; 3:133146.

23 Akhtar N, Padilla ML, Dickerson EB, et al. Interleukin-12 inhibits tumor growth in a novel angiogenesis canine hemangiosarcoma xenograft model. Neoplasia 2004; 6:106-116.

24 Lotze MT, Zitvogel L, Campbell R, et al. Cytokine gene therapy of cancer using interleukin-12: murine and clinical trials. Ann N Y Acad Sci 1996; 795:440-454.

25 Narvaiza I, Mazzolini G, Barajas M, et al. Intratumoral coinjection of two adenoviruses, one encoding the chemokine IFN-gamma-inducible protein-10 and another encoding IL12, results in marked antitumoral synergy. J Immunol. 2000; 164:3112-3122.

26 Cervenak L, Morbidelli L, Donati D, et al. Abolished angiogenicity and tumorigenicity of Burkitt lymphoma by interleukin10. Blood 2000; 96:2568-2573.

27 Feldman AL, Friedl J, Lans TE, et al. Retroviral gene transfer of interferon-inducible protein 10 inhibits growth of human melanoma xenografts. Int J Cancer 2002; 99:149-153.

28 Putzer BM, Hitt M, Muller WJ, et al. Interleukin 12 and B7-1 costimulatory molecule expressed by an adenovirus vector act synergistically to facilitate tumor regression. Proc Natl Acad Sci U S A 1997; 94:10889-1094.

29 Emtage PC, Wan Y, Hitt M, et al. Adenoviral vectors expressing lymphotactin and interleukin 2 or lymphotactin and interleukin 12 synergize to facilitate tumor regression in murine breast cancer models. Hum Gene Ther 1999; 10:697-6709.

30 Charames GS, Bapat B. Genomic instability and cancer. Curr Mol Med 2003; 3:589-596.

31 Meng RD, El-Deiry WS. Tumor suppressor genes as targets for cancer gene therapy. In: Lattime EC, Gerson SL, Eds. Gene therapy of cancer. San Diego: Academic Press, CA, 1999:320.

32 Greenblatt MS, Bennett WP, Hollstein M, Harris CC. Mutations in the p53 tumor suppressor gene: clues to cancer etiology and molecular pathogenesis. Cancer Res 1994; 54:4855-4878.

33 Zeimet AG, Riha K, Berger J, et al. New insights into p53 regulation and gene therapy for cancer. Biochem Pharmacol 2000; 60:1153-1163.

34 Eastham JA, Grafton W, Martin CM, Williams BJ. Suppression of primary tumor growth and the progression to metastasis with p53 adenovirus in human prostate cancer. J Urol 2000; 164:814819.

35 Schumacher G, Bruckheimer EM, Beham AW, et al. Molecular determinants of cell death induction following adenovirus-mediated gene transfer of wild-type p53 in prostate cancer cells. Int J Cancer 2001; 91:159-166.

36 Cirielli C, Inyaku K, Capogrossi MC, Yuan X, Williams JA. Adenovirus-mediated wild-type p53 expression induces apoptosis and suppresses tumorigenesis of experimental intracranial human malignant glioma. J Neurooncol 1999; 43:99-108.

37 Abe T, Wakimoto H, Bookstein R, et al. Intra-arterial delivery of p53-containing adenoviral vector into experimental brain tumors. Cancer Gene Ther 2002; 9:228-235.

38 Lee MH, Yang HY. Negative regulators of cyclin-dependent kinases and their roles in cancers. Cell Mol Life Sci 2001; 58:1907-1922.

39 Brown VL, Harwood CA, Crook T, et al. p16INK4a and p14ARF tumor suppressor genes are commonly inactivated in cutaneous squamous cell carcinoma. J Invest Dermatol 2004; 122:12841292.

40 Kobayashi S, Shirasawa H, Sashiyama H, et al. P16INK4a expression adenovirus vector to suppress pancreas cancer cell proliferation. Clin Cancer Res 1999; 5:4182-4185.

41 Campbell I, Magliocco A, Moyana T, Zheng C, Xiang J. Adenovirus-mediated p16INK4 gene transfer significantly suppresses human breast cancer growth. Cancer Gene Ther 2000; 7:12701278.

42 Kim SK, Wang KC, Cho BK, et al. Interaction between p53 and $\mathrm{p} 16$ expressed by adenoviral vectors in human malignant glioma cell lines. J Neurosurg 2002; 97:143-150.

43 Sandig V, Brand K, Herwig S, et al. Adenovirally transferred p16INK4/CDKN2 and p53 genes cooperate to induce apoptotic tumor cell death. Nat Med 1997; 3:313-319.

44 Shinoura N, Muramatsu Y, Nishimura M, et al. Adenovirusmediated transfer of p33ING1 with p53 drastically augments apoptosis in gliomas. Cancer Res 1999; 59:5521-5528.

45 van Dillen IJ, Mulder NH, Vaalburg W, de Vries EF, Hospers GA. Influence of the bystander effect on HSV-tk/GCV gene therapy. A review. Curr Gene Ther 2002; 2:307-322.

46 Chen SH, Shine HD, Goodman JC, Grossman RG, Woo SL. Gene therapy for brain tumors: regression of experimental gliomas by adenovirus-mediated gene transfer in vivo. Proc Natl Acad Sci U S A 1994; 91:3054-3057.

$47 \mathrm{Kwon} \mathrm{HC}$, Kim JH, Kim KC, et al. In vivo antitumor effect of herpes simplex virus thymidine kinase gene therapy in rat hepatocellular carcinoma: feasibility of adenovirus-mediated intra-arterial gene delivery. Mol Cells 2001; 11:170-178.

48 Maatta AM, Tenhunen A, Pasanen T, et al. Non-small cell lung cancer as a target disease for herpes simplex type 1 thymidine kinase-ganciclovir gene therapy. Int J Oncol 2004; 24:943949.

49 Rosenfeld ME, Wang M, Siegal GP, et al. Adenoviral-mediated delivery of herpes simplex virus thymidine kinase results in tumor reduction and prolonged survival in a SCID mouse model of human ovarian carcinoma. J Mol Med 1996; 74:455-462.

50 Alvarez RD, Gomez-Navarro J, Wang M, et al. Adenoviralmediated suicide gene therapy for ovarian cancer. Mol Ther 2000; 2:524-530.

51 Kubo H, Gardner TA, Wada Y, et al. Phase I dose escalation clinical trial of adenovirus vector carrying osteocalcin promoterdriven herpes simplex virus thymidine kinase in localized and metastatic hormone-refractory prostate cancer. Hum Gene Ther 2003; 14:227-241.

52 Germano IM, Fable J, Gultekin SH, Silvers A. Adenovirus/herpes simplex-thymidine kinase/ganciclovir complex: preliminary results of a phase I trial in patients with recurrent malignant gliomas. J Neurooncol 2003; 65:279-289.

53 Ueno M, Koyama F, Yamada Y, et al. Tumor-specific chemoradio-gene therapy for colorectal cancer cells using adenovirus vector expressing the cytosine deaminase gene. Anticancer Res 
2001; 21:2601-2608.

54 Rogulski KR, Wing MS, Paielli DL, et al. Double suicide gene therapy augments the antitumor activity of a replicationcompetent lytic adenovirus through enhanced cytotoxicity and radiosensitization. Hum Gene Ther 2000; 11:67-76.

55 Adachi Y, Tamiya T, Ichikawa T, et al. Experimental gene therapy for brain tumors using adenovirus-mediated transfer of cytosine deaminase gene and uracil phosphoribosyltransferase gene with 5-fluorocytosine. Hum Gene Ther 2000; 11:77-89.

56 Ju DW, Tao Q, Cheng DS, et al. Adenovirus-mediated lymphotactin gene transfer improves therapeutic efficacy of cytosine deaminase suicide gene therapy in established murine colon carcinoma. Gene Ther 2000; 7:329-338.

57 Pooley JL, Heath WR, Shortman K. Cutting edge: intravenous soluble antigen is presented to CD4 T cells by CD8- dendritic cells, but cross-presented to CD8 T cells by CD8+ dendritic cells. J Immunol 2001; 166:5327-30.

58 Sanchez-Torres C, Garcia-Romo GS, Cornejo-Cortes MA, Rivas-Carvalho A, Sanchez-Schmitz G. CD16+ and CD16- human blood monocyte subsets differentiate in vitro to dendritic cells with different abilities to stimulate CD4+ T cells. Int Immunol 2001; 13:1571-1581.

59 Lutz MB, Kukutsch N, Ogilvie AL, et al. An AdVsanced culture method for generating large quantities of highly pure dendritic cells from mouse bone marrow. J Immunol Methods 1999; 223:77-92.

60 Lutz MB, Suri RM, Niimi M, et al. Immature dendritic cells generated with low doses of GM-CSF in the absence of IL-4 are maturation resistant and prolong allograft survival in vivo. Eur J Immunol 2000; 30:1813-1822.

61 Cella M, Sallusto F, Lanzavecchia A. Origin, maturation and antigen presenting function of dendritic cells. Curr Opin Immunol 1997; 9:10-16.

62 Ishii KJ, Suzuki K, Coban C, et al. Genomic DNA released by dying cells induces the maturation of APCs. J Immunol 2001; 167:2602-2607.

63 Rescigno M, Granucci F, Ricciardi-Castagnoli P. Molecular events of bacterial-induced maturation of dendritic cells. J Clin Immunol 2000; 20:161-166.

64 Maraskovsky E, Daro E, Roux E, et al. In vivo generation of human dendritic cell subsets by Flt3 ligand. Blood 2000; 96:878874.

65 Masten BJ, Olson GK, Kusewitt DF, Lipscomb MF. Flt3 ligand preferentially increases the number of functionally active myeloid dendritic cells in the lungs of mice. J Immunol 2004; 172:4077-4083.

66 Liu Y, Santin AD, Mane M, et al. Transduction and utility of the granulocyte-macrophage colony-stimulating factor gene into monocytes and dendritic cells by adeno-associated virus. J Interferon Cytokine Res 2000; 20:21-30.

67 Celluzzi CM, Mayordomo JI, Storkus WJ, Lotze MT, Falo LD Jr. Peptide-pulsed dendritic cells induce antigen-specific CTL-mediated protective tumor immunity. J Exp Med 1996; 183:283-287.

68 Toes RE, van der Voort EI, Schoenberger SP, et al. Enhancement of tumor outgrowth through CTL tolerization after peptide vaccination is avoided by peptide presentation on dendritic cells. $\mathrm{J}$ Immunol 1998; 160:4449-4456.

69 Banchereau J, Palucka AK, Dhodapkar M, et al. Immune and clinical responses in patients with metastatic melanoma to CD34(+) progenitor-derived dendritic cell vaccine. Cancer Res 2001; 61:6451-6458.

70 Lau R, Wang F, Jeffery G, et al. Phase I trial of intravenous peptide-pulsed dendritic cells in patients with metastatic melanoma. J Immunother 2001; 24:66-78.

71 Kershaw MH, Hsu C, Mondesire W, et al. Immunization against endogenous retroviral tumor-associated antigens. Cancer Res 2001; 61:7920-7924.

72 Fong L, Hou Y, Rivas A, et al. Altered peptide ligand vaccination with Flt3 ligand expanded dendritic cells for tumor immunotherapy. Proc Natl Acad Sci U S A 2001; 98:8809-8814.

73 Brugger W, Schneider A, Schammann T, et al. Dendritic cellbased vaccines in patients with hematological malignancies. Ann N Y Acad Sci 2001; 938:359-362.

74 Yasukawa M, Ohminami H, Kojima K, et al. HLA class IIrestricted antigen presentation of endogenous bcr-abl fusion protein by chronic myelogenous leukemia-derived dendritic cells to CD4(+) T lymphocytes. Blood 2001; 98:1498-1505.

75 De Bruijn ML, Schuurhuis DH, Vierboom MP, et al. Immunization with human papillomavirus type 16 (HPV16) oncoproteinloaded dendritic cells as well as protein in adjuvant induces MHC class I-restricted protection to HPV16-induced tumor cells. Cancer Res 1998; 58:724-731.

76 Heimberger AB, Archer GE, Crotty LE, et al. Dendritic cells pulsed with a tumor-specific peptide induce long-lasting immunity and are effective against murine intracerebral melanoma. Neurosurgery 2002; 50:158-164.

77 Fields RC, Shimizu K, Mule JJ. Murine dendritic cells pulsed with whole tumor lysates mediate potent antitumor immune responses in vitro and in vivo. Proc Natl Acad Sci U S A 1998; 95:9482-9487.

78 Tatsumi T, Takehara T, Kanto T, et al. Administration of interleukin-12 enhances the therapeutic efficacy of dendritic cell-based tumor vaccines in mouse hepatocellular carcinoma. Cancer Res 2001; 61:7563-7567.

79 Ni HT, Spellman SR, Jean WC, Hall WA, Low WC. Immunization with dendritic cells pulsed with tumor extract increases survival of mice bearing intracranial gliomas. J Neurooncol 2001; 51:1-9.

80 Schnurr M, Galambos P, Scholz C, et al. Tumor cell lysate-pulsed human dendritic cells induce a T-cell response against pancreatic carcinoma cells: an in vitro model for the assessment of tumor vaccines. Cancer Res 2001; 61:6445-6450.

81 Yoshida S, Morii K, Watanabe M, et al. The generation of antitumoral cells using dentritic cells from the peripheral bloood of patients with malignant brain tumors. Cancer Immunol Immunother 2001; 50:321-327.

82 Nestle FO, Alijagic S, Gilliet M, et al. Vaccination of melanoma patients with peptide- or tumor lysate-pulsed dendritic cells. Nat Med 1998; 4:328-332.

83 Geiger JD, Hutchinson RJ, Hohenkirk LF, et al. Vaccination of pediatric solid tumor patients with tumor lysate-pulsed dendritic cells can expand specific T cells and mediate tumor regression. Cancer Res 2001; 61:8513-8519.

84 Mulders P, Tso CL, Gitlitz B, et al. Presentation of renal tumor antigens by human dendritic cells activates tumor-infiltrating lymphocytes against autologous tumor: implications for live kidney cancer vaccines. Clin Cancer Res 1999; 5:445-454. 
85 Kurokawa T, Oelke M, Mackensen A. Induction and clonal expansion of tumor-specific cytotoxic $\mathrm{T}$ lymphocytes from renal cell carcinoma patients after stimulation with autologous dendritic cells loaded with tumor cells. Int J Cancer 2001; 91:749-756.

86 Santin AD, Bellone S, Ravaggi A, et al. Induction of tumourspecific CD8(+) cytotoxic T lymphocytes by tumour lysatepulsed autologous dendritic cells in patients with uterine serous papillary cancer. Br J Cancer 2002; 86:151-157.

87 Boczkowski D, Nair SK, Nam JH, Lyerly HK, Gilboa E. Induction of tumor immunity and cytotoxic T lymphocyte responses using dendritic cells transfected with messenger RNA amplified from tumor cells. Cancer Res 2000; 60:1028-1034.

88 Nair SK, Morse M, Boczkowski D, et al. Induction of tumorspecific cytotoxic $\mathrm{T}$ lymphocytes in cancer patients by autologous tumor RNA-transfected dendritic cells. Ann Surg 2002; 235:540-549.

89 Van Tendeloo VF, Ponsaerts P, Lardon F, et al. Highly efficient gene delivery by mRNA electroporation in human hematopoietic cells: superiority to lipofection and passive pulsing of mRNA and to electroporation of plasmid cDNA for tumor antigen loading of dendritic cells. Blood 2001; 98:49-56.

90 Eppler E, Horig H, Kaufman HL, Groscurth P, Filgueira L. Carcinoembryonic antigen (CEA) presentation and specific $\mathrm{T}$ cell-priming by human dendritic cells transfected with CEAmRNA. Eur J Cancer 2002; 38:184-193.

91 Honda K, Sakaguchi S, Nakajima C, et al. Selective contribution of IFN-alpha/beta signaling to the maturation of dendritic cells induced by double-stranded RNA or viral infection. Proc Natl Acad Sci U S A 2003; 100:10872-10877.

92 Weissman D, Ni H, Scales D, et al. HIV gag mRNA transfection of dendritic cells (DC) delivers encoded antigen to MHC class I and II molecules, causes DC maturation, and induces a potent human in vitro primary immune response. J Immunol 2000; 165:4710-4717.

93 Rains N, Cannan RJ, Chen W, Stubbs RS. Development of a dendritic cell (DC)-based vaccine for patients with AdVsanced colorectal cancer. Hepatogastroenterology 2001; 48:347-351.

94 Schmitt WE, Stassar MJ, Schmitt W, Little M, Cochlovius B. In vitro induction of a bladder cancer-specific T-cell response by mRNA-transfected dendritic cells. J Cancer Res Clin Oncol 2001; 127:203-206.

95 Larsson M, Fonteneau JF, Bhardwaj N. Dendritic cells resurrect antigens from dead cells. Trends Immunol 2001; 22:141-148.

96 Fonteneau JF, Larsson M, Bhardwaj N. Dendritic cell-dead cell interactions: implications and relevance for immunotherapy. J Immunother 2001; 24:294-304.

97 Fadok VA, Bratton DL, Rose DM, et al. A receptor for phosphatidylserine-specific clearance of apoptotic cells. Nature 2000; 405:85-90.

98 Basu S, Binder RJ, Suto R, Anderson KM, Srivastava PK. Necrotic but not apoptotic cell death releases heat shock proteins, which deliver a partial maturation signal to dendritic cells and activate the NF-kappa B pathway. Int Immunol 2000; 12:15391546.

99 Binder RJ, Han DK, Srivastava PK. CD91: a receptor for heat shock protein gp96. Nat Immunol 2000; 1:151-155.

100 Delamarre L, Holcombe H, Mellman I. Presentation of exogenous antigens on major histocompatibility complex (MHC) class I and MHC class II molecules is differentially regulated during dendritic cell maturation. J Exp Med 2003; 198:111122.

101 Berard F, Blanco P, Davoust J, et al. Cross-priming of naive CD8 T cells against melanoma antigens using dendritic cells loaded with killed allogeneic melanoma cells. J Exp Med 2000; 192:1535-1544.

102 Jenne L, Arrighi JF, Jonuleit H, Saurat JH, Hauser C. Dendritic cells containing apoptotic melanoma cells prime human $\mathrm{CD} 8+$ $\mathrm{T}$ cells for efficient tumor cell lysis. Cancer Res 2000; 60:44464452.

103 Matzinger P. Tolerance, danger and the extended family. Annu Rev Immunol 1994; 12:991-1045.

104 Sauter B, Albert ML, Francisco L, et al. Consequences of cell death: Exposure to necrotic tumor cells, but not primary tissue cells or apoptotic cells, induces the maturation of immunostimulatory dendritic cells. J Exp Med 2000; 191:423-433.

105 Steinman RM, Turley S, Mellman I, et al. The induction of tolerance by dendritic cells that have captured apoptotic cells. J Exp Med 2000; 191:411-416.

106 Rovere P, Vallinoto C, Bondanza A, et al. Bystander apoptosis triggers dendritic cell maturation and antigen-presenting function. J Immunol 1998; 161:4467-4471.

107 Rovere P, Sabbadini MG, Vallinoto C, et al. Delayed clearance of apoptotic lymphoma cells allows cross-presentation of intracellular antigens by mature dendritic cells. J Leukoc Biol 1999; 66:345-349.

108 Pietra G, Mortarini R, Parmiani G, et al. Phases of apoptosis of melanoma cells, but not of normal melanocytes, differently affect maturation of myeloid dendritic cells. Cancer Res 2001; 61:8218-8226.

109 Kotera Y, Shimizu K, Mule JJ. Comparative analysis of necrotic and apoptotic tumor cells as a source of antigen(s) in dendritic cell-based immunization. Cancer Res 2001; 61:8105-8109.

110 Feng H, Zeng Y, Whitesell L, et al. Stressed apoptotic tumor cells express heat shock proteins and elicit tumor-specific immunity. Blood 2001; 97:3505-3512.

111 Zheng H, Dai J, Stoilova D, et al. Cell surface targeting of heat shock protein gp96 induces dendritic cell maturation and antitumor immunity. J Immunol 2001; 167:6731-6735.

112 Chen Z, Moyana T, Saxena A, et al. Efficient antitumor immunity derived from maturation of dendritic cells that had phagocytosed apoptotic/necrotic tumor cells. Int J Cancer 2001; 93:539-548.

113 Rughetti A, Biffoni M, Sabbatucci M, et al. Transfected human dendritic cells to induce antitumor immunity. Gene Ther 2000; 7:1458-1466.

114 Irvine AS, Trinder PK, Laughton DL, et al. Efficient nonviral transfection of dendritic cells and their use for in vivo immunization. Nat Biotechnol 2000; 18:1273-1278.

115 Wei Y, Li J, Chen WY, et al. Enhanced transgene expression and effective in vivo antitumor immune responses initiated by dendritic progenitors transfected with a nonviral $\mathrm{T} 7$ vector expressing a model tumor antigen. J Immunother 2000; 23:7582.

116 Di Nicola M, Carlo-Stella C, Milanesi M, et al. Large-scale feasibility of gene transduction into human CD34+ cell-derived dendritic cells by adenoviral/polycation complex. Br J Haematol 2000; 111:344-350. 
117 Lapointe R, Royal RE, Reeves ME, et al. Retrovirally transduced human dendritic cells can generate $\mathrm{T}$ cells recognizing multiple MHC class I and class II epitopes from the melanoma antigen glycoprotein 100. J Immunol 2001; 167:4758-4764.

118 Willis RA, Bowers WJ, Turner MJ, et al. Dendritic cells transduced with HSV-1 amplicons expressing prostate-specific antigen generate antitumor immunity in mice. Hum Gene Ther 2001; 12:1867-1879.

119 Ponnazhagan S, Mahendra G, Curiel DT, Shaw DR. Adeno-associated virus type 2-mediated transduction of human monocytederived dendritic cells: implications for ex vivo immunotherapy. J Virol 2001; 75:9493-9501.

120 Motta I, Andre F, Lim A, et al. Cross-presentation by dendritic cells of tumor antigen expressed in apoptotic recombinant canarypox virus-infected dendritic cells. J Immunol 2001; 167:1795-1802.

121 Maruyama K, Akiyama Y, Nara-Ashizawa N, et al. AdenovirusMediated MUC1 gene transduction into human blood-derived dendritic cells. J Immunother 2001; 24:345-353.

122 Xia D, Zheng S, Zhang W, et al. Effective induction of therapeutic antitumor immunity by dendritic cells coexpressing interleukin-18 and tumor antigen. J Mol Med 2003; 81:585596.

123 Klein C, Bueler H, Mulligan RC. Comparative analysis of genetically modified dendritic cells and tumor cells as therapeutic cancer vaccines. J Exp Med 2000; 191:1699-1708.

124 Ribas A, Butterfield LH, Hu B, et al. Generation of T-cell immunity to a murine melanoma using MART-1-engineered dendritic cells. J Immunother 2000; 23:59-66.

125 Steitz J, Bruck J, Knop J, Tuting T. Adenovirus-transduced dendritic cells stimulate cellular immunity to melanoma via a CD4(+) T cell-dependent mechanism. Gene Ther 2001; 8:12551263.

126 Nikitina EY, Clark JI, Van Beynen J, et al. Dendritic cells transduced with full-length wild-type p53 generate antitumor cytotoxic $\mathrm{T}$ lymphocytes from peripheral blood of cancer patients. Clin Cancer Res 2001; 7:127-135.

127 Okada N, Masunaga Y, Okada Y, et al. Dendritic cells transduced with gp100 gene by RGD fiber-mutant adenovirus vectors are highly efficacious in generating anti-B16BL6 melanoma immunity in mice. Gene Ther 2003; 10:1891-1902.

128 Linette GP, Shankara S, Longerich S, et al: In vitro priming with adenovirus/gp100 antigen-transduced dendritic cells reveals the epitope specificity of HLA-A*0201-restricted $\mathrm{CD}^{+} \mathrm{T}$ cells in patients with melanoma. J Immunol 2000; 164:3402-3412.

129 Butterfield LH, Jilani SM, Chakraborty NG, et al. Generation of melanoma-specific cytotoxic T lymphocytes by dendritic cells transduced with a MART-1 adenovirus. J Immunol 1998; 161:5607-5613.

130 Chen Y, Emtage P, Zhu Q, et al. Induction of ErbB-2/neu-specific protective and therapeutic antitumor immunity using genetically modified dendritic cells: enhanced efficacy by cotransduction of gene encoding IL-12. Gene Ther 2001; 8:316-323.

131 zum Buschenfelde CM, Metzger J, Hermann C, et al. The generation of both $\mathrm{T}$ killer and $\mathrm{Th}$ cell clones specific for the tumor-associated antigen HER2 using retrovirally transduced dendritic cells. J Immunol 2001; 167:1712-1719.

132 Kirk CJ, Mule JJ. Gene-modified dendritic cells for use in tumor vaccines. Hum Gene Ther 2000; 11:797-806.
133 Curiel-Lewandrowski C, Mahnke K, Labeur M, et al. Transfection of immature murine bone marrow-derived dendritic cells with the granulocyte-macrophage colony-stimulating factor gene potently enhances their in vivo antigen-presenting capacity. J Immunol 1999; 163:174-183.

134 Zhang W, Chen Z, Li F, et al. Tumour necrosis factor-alpha (TNF-alpha) transgene-expressing dendritic cells (DCs) undergo augmented cellular maturation and induce more robust T-cell activation and anti-tumour immunity than DCs generated in recombinant TNF-alpha. Immunology 2003; 108:177-188.

135 Tatsumi T, Huang J, Gooding WE, et al. Intratumoral delivery of dendritic cells engineered to secrete both interleukin (IL)-12 and IL-18 effectively treats local and distant disease in association with broadly reactive Tc1-type immunity. Cancer Res 2003; 63:6378-6386.

136 Matsuyoshi H, Senju S, Hirata S, et al. Enhanced priming of antigen-specific CTLs in vivo by embryonic stem cell-derived dendritic cells expressing chemokine along with antigenic protein: application to antitumor vaccination. J Immunol 2004; 172:776-786.

137 Xia DJ, Zhang WP, Zheng S, et al. Lymphotactin cotransfection enhances the therapeutic efficacy of dendritic cells genetically modified with melanoma antigen gp100. Gene Ther 2002; 9:592601.

138 Liu Y, Zhang X, Zhang W, et al. Adenovirus-mediated CD40 ligand gene-engineered dendritic cells elicit enhanced CD8(+) cytotoxic T-cell activation and antitumor immunity. Cancer Gene Ther 2002; 9:202-208.

139 Ozawa H, Ding W, Torii H, et al. Granulocyte-macrophage colony-stimulating factor gene transfer to dendritic cells or epidermal cells augments their antigen-presenting function including induction of anti-tumor immunity. J Invest Dermatol 1999; 113:999-1005.

140 Lamont AG, Adorini L. IL-12: a key cytokine in immune regulation. Immunol Today 1996; 17:214-217.

141 Akiyama Y, Watanabe M, Maruyama K, et al. Enhancement of antitumor immunity against B16 melanoma tumor using genetically modified dendritic cells to produce cytokines. Gene Ther 2000; 7:2113-2121.

142 Furumoto K, Arii S, Yamasaki S, et al. Spleen-derived dendritic cells engineered to enhance interleukin-12 production elicit therapeutic antitumor immune responses. Int J Cancer 2000; 87:665-672.

143 Vitiello PF, Rausch MP, Horowitz KM, Kurt RA. Secondary lymphoid-tissue chemokine induced modulation of T cells. Immunol Invest 2004; 33:235-249.

144 Perez-Diez A, Spiess PJ, Restifo NP, Matzinger P, Marincola FM. Intensity of the vaccine-elicited immune response determines tumor clearance. J Immunol 2002; 168:338-347.

145 Hsieh CL, Pang VF, Chen DS, Hwang LH. Regression of established mouse leukemia by GM-CSF-transduced tumor vaccine: implications for cytotoxic T lymphocyte responses and tumor burdens. Hum Gene Ther. 1997; 8:1843-1854.

146 Liu Y, Saxena A, Zheng C, Carlsen S, Xiang J. Combined alpha tumor necrosis factor gene therapy and engineered dendritic cell vaccine in combating well-established tumors. J Gene Med. 2004; 6:857-868.

147 Liu Y, Xia D, Li F, Zheng C, Xiang J. Intratumoral administration of immature dendritic cells following the adenovirus vector en- 
coding CD40 ligand elicits significant regression of established myeloma. Cancer Gene Ther 2005; 12:122-132.

148 Tracey KJ, Cerami A. Tumor necrosis factor: a pleiotropic cytokine and therapeutic target. Annu Rev Med 1994; 45:491-503.

149 Fukumura D, Salehi HA, Witwer B, et al. Tumor necrosis factor alpha-induced leukocyte adhesion in normal and tumor vessels: effect of tumor type, transplantation site, and host strain. Cancer Res 1995; 55:4824-4829.

150 Mizuguchi H, Nakagawa T, Toyosawa S, et al. Tumor necrosis factor alpha-mediated tumor regression by the in vivo transfer of genes into the artery that leads to tumors. Cancer Res 1998; 58:5725-5730.

151 Brunner C, Seiderer J, Schlamp A, et al. Enhanced dendritic cell maturation by TNF-alpha or cytidine-phosphate-guanosine DNA drives T cell activation in vitro and therapeutic anti-tumor immune responses in vivo. J Immunol 2000; 165:6278-6286.

152 Spriggs DR, Sherman ML, Michie H, et al. Recombinant human tumor necrosis factor administered as a 24-hour intravenous infusion. A phase I and pharmacologic study. J Natl Cancer Inst 1988; 80:1039-1044.

153 Feinberg B, Kurzrock R, Talpaz M, et al. A phase I trial of intravenously-administered recombinant tumor necrosis factor-alpha in cancer patients. J Clin Oncol 1988; 6:1328-1334.

154 Madhusudan S, Foster M, Muthuramalingam SR, et al. A phase II study of etanercept (Enbrel), a tumor necrosis factor alpha inhibitor in patients with metastatic breast cancer. Clin Cancer Res 2004; 10:6528-6534.

155 Lienard D, Ewalenko P, Delmotte JJ, Renard N, Lejeune FJ. High-dose recombinant tumor necrosis factor alpha in combination with interferon gamma and melphalan in isolation perfusion of the limbs for melanoma and sarcoma. J Clin Oncol 1992; 10:52-60.

156 Xiang J, Qi Y, Chen Y. Inhibition of established tumor growth in syngeneic mice by local inoculation of engineered mouse myeloma cells secreting a recombinant fusion protein RM4/TNF. Cancer Gene Ther 1997; 4:353-358.

157 Lu Y, Yamauchi N, Koshita Y, et al. Administration of subtumor regression dosage of TNF-alpha to mice with pre-existing parental tumors augments the vaccination effect of TNF genemodified tumor through the induction of MHC class I molecule. Gene Ther 2001; 8:499-507.
158 Marr RA, Addison CL, Snider D, et al. Tumour immunotherapy using an adenoviral vector expressing a membrane-bound mutant of murine TNF alpha. Gene Ther 1997; 4:1181-1188.

159 Marr RA, Hitt M, Gauldie J, Muller WJ, Graham FL. A p75 tumor necrosis factor receptor-specific mutant of murine tumor necrosis factor alpha expressed from an adenovirus vector induces an antitumor response with reduced toxicity. Cancer Gene her 1999; 6:465-474.

160 Wright P, Braun R, Babiuk L, et al. Adenovirus-mediated TNFalpha gene transfer induces significant tumor regression in mice. Cancer Biother Radiopharm 1999; 14:49-57.

161 Grewal IS and Flavell RA. CD40 and CD154 in cell-mediated immunity. Annu Rev Immunol 1998; 16:111-135.

162 Schoenberger SP, Toes RE, van der Voort EI, Offringa R, Melief CJ. T-cell help for cytotoxic T lymphocytes is mediated by CD40-CD40L interactions. Nature 1998; 393:480-483.

163 Bancherau J, Steinman RM. Dendritic cells and the control of immunity. Nature 1998; 392:245-252.

164 Hart DN. Dendritic cells: unique leukocytes populations which control the primary immune response. Blood 1997; 90:32453287.

165 Shreedhar V, Moodycliffe AM,Ullrich SE, et al. Dendritic cells require T cells for functional maturation in vivo. Immunity 1999; 11:625-636.

166 Moodycliffe AM, Shreedhar V, Ullrich SE, et al. CD40-CD40 ligand interactions in vivo regulate migration of antigen-bearing dendritic cells from the skin to draining lymph nodes. J Exp Med 2000; 191:2011-2020.

167 Schuurhuis DH, Laban S, Toes RE, et al. Immature dendritic cells acquire $\mathrm{CD} 8^{+}$cytotoxic $\mathrm{T}$ lymphocyte priming capacity upon activation by $\mathrm{T}$ helper cell-independent or -dependent stimuli. J Exp Med 2000; 192:145-150.

168 Kelleher M, Beverley PC. Lipopolysaccharide modulation of dendritic cells is insufficient to mature dendritic cells to generate CTLs from naive polyclonal $\mathrm{CD}^{+} \mathrm{T}$ cells in vitro, whereas CD40 ligation is essential. J Immunol 2001; 167:6247-6255.

169 Watanabe S, Kagamu H, Yoshizawa H, et al. The Duration of Signaling through CD40 Directs Biological Ability of Dendritic Cells to Induce Antitumor Immunity. J Immunol 2003; 171:5828-5836.

Edited by Yufang Shi 